\title{
Numerical Simulation of Response Characteristics of Audio-magnetotelluric for Gas Hydrate in the Qilian Mountain Permafrost, China
}

\author{
Kun XIAO ${ }^{1,2}$, Changchun $\mathrm{ZOU}^{2}$, Changqing $\mathrm{YU}^{3}$, and Jinyun $\mathrm{PI}^{3}$ \\ ${ }^{1}$ School of Nuclear Engineering and Geophysics, East China University \\ of Technology, Nanchang, People's Republic of China \\ ${ }^{2}$ School of Geophysics and Information Technology, China University \\ of Geosciences (Beijing), Beijing, People's Republic of China; \\ e-mail: xiaokun0626@163.com (corresponding author) \\ ${ }^{3}$ Institute of Geology, Chinese Academy of Geological Sciences, \\ Beijing, People's Republic of China
}

\begin{abstract}
Audio-magnetotelluric (AMT) method is a kind of frequencydomain sounding technique, which can be applied to gas hydrate prospecting and assessments in the permafrost region due to its high frequency band. Based on the geological conditions of gas hydrate reservoir in the Qilian Mountain permafrost, by establishing high-resistance abnormal model for gas hydrate and carrying out numerical simulation using finite element method (FEM) and nonlinear conjugate gradient (NLCG) method, this paper analyzed the application range of AMT method and the best acquisition parameters setting scheme. When porosity of gas hydrate reservoir is less than $5 \%$, gas hydrate saturation is greater than $70 \%$, occurrence scale is less than $50 \mathrm{~m}$, or bury depth is greater than $500 \mathrm{~m}$, AMT technique cannot identify and delineate the favorable gas hydrate reservoir. Survey line should be more than twice the length of probable occurrence scale, while tripling the length will make the best result. The number of stations should be no less than 6 , and 11
\end{abstract}

Ownership: Institute of Geophysics, Polish Academy of Sciences;

(C) 2015 Xiao et al. This is an open access article distributed under the Creative Commons Attribution-NonCommercial-NoDerivs license,

http://creativecommons.org/licenses/by-nc-nd/3.0/. 
stations are optimal. At the high frequency section $(10 \sim 1000 \mathrm{~Hz})$, there should be no less than 3 frequency points, 4 being the best number.

Key words: Qilian Mountain permafrost, gas hydrate, AMT, response characteristic, numerical simulation.

\section{INTRODUCTION}

Gas hydrate is a solid crystal with cage structure consisting of water molecules and natural gas (mainly $\mathrm{CH}_{4}$ ), which mainly exists in the terrestrial permafrost regions and beneath the sea along the outer continental margins of the world's oceans (Sloan 1998). In permafrost regions, gas hydrates may exist at subsurface depths ranging from about 130 to $2000 \mathrm{~m}$ (Collett 2002, Collett et al. 2011, Lu et al. 2011). Gas hydrates in offshore continental margins have been mapped at depths below the sea floor ranging from about 100 to $1100 \mathrm{~m}$ (Collett 2002, Dickens 2001, Huo and Zhang 2009, Xiao et al. 2013, Yang et al. 2014). As a new clean alternative energy source of huge reserve, gas hydrates have attracted more and more attention, and more than 100 regions have directly or indirectly found the occurrence zones (Boswell and Collett 2011, Moridis et al. 2011). In November 2008, gas hydrate samples were recovered in the Qilian Mountain permafrost, Qinghai Province of China (Zhu et al. 2010, Lu et al. 2011). This is the first discovery of gas hydrate in China's permafrost and in the low-middle latitude permafrost of the world. The Qilian Mountain permafrost region may be the most promising strategic area for gas hydrate (Wang 2010, Zhao et al. 2013).

In recent years, in order to further optimize the promising areas of gas hydrate, and to provide support for drilling deployment to explore gas hydrate, gas hydrate AMT sounding project has been launched. Field data acquisition and indoor data processing have been underway. AMT survey has already displayed its unusual advantages in prospecting for metal ore, terrestrial heat and geological structures (Schnegg et al. 1983, Clerc et al. 1984, Bronner and Fourno 1992, Ogawa et al. 1994, Balyavskii and Sukhoi 2004, Santos et al. 2006, 2007; Strangway et al. 1973, Yamaguchi et al. 2010, Abdelzaher et al. 2011). However, because research on the gas hydrate in the permafrost region in our country has been at its very early stage, the AMT method is rarely used to prospect for gas hydrates and few related reports come into sight. Determining appropriate survey line length, station spacing and the number of frequency points which must be considered in the field data acquisition, will be convenient to indoor AMT data processing and interpretation. Generally, more stations can bring abundant information for indoor data interpretation, while human and financial investments increase correspondingly, which may reduce the efficiency of field data acquisition. As a result, how to realize an efficient field data acquisition with reasonable 
cost is a problem to be solved urgently. Due to the different occurrences of gas hydrate in the Qilian Mountain permafrost region, resistivity, occurrence scale, and bury depth of gas hydrate vary a lot, and the corresponding AMT response modes are unclear, making data processing and interpretation difficult. Therefore, in order to provide some technical support for the gas hydrate prospecting, it is necessary to carry out numerical simulation on AMT response characteristics of different gas hydrate reservoirs.

Based on the geological conditions of gas hydrate in the Qilian Mountain permafrost, by establishing high-resistivity anomaly model for gas hydrate and carrying out forward modeling with finite element method, this paper obtained the AMT response characteristics of the corresponding models. By further analyzing the response characteristics of different gas hydrate reservoirs, application range of AMT method was attained. Nonlinear conjugate gradient method (NLCG) was used to simulate AMT response characteristics under the conditions of different acquisition parameters, including survey line length, station spacing, and number of frequency points. Through comparing and analyzing the differences of response characteristics resulted from different acquisition parameters, an acquisition parameter setting scheme in favor of prospecting gas hydrate reservoir in the study area was obtained.

\section{GEOLOGICAL SETTING}

\subsection{Geotectonics and stratigraphic characteristics}

Qilian Mountain is located in the northeastern part of the Qinghai-Tibetan Plateau in China. Its tectonic units are usually divided into the northern Qilian belt, the middle Qilian land, and the southern Qilian belt. This area had a complex history, experiencing a continental rift stage (Sinian to Middle Cambrian), an ocean expansion and trench-arc-basin formation stage (Late Cambrian to Middle Ordovician), and an orogenic stage (thrust-down orogeny, collision orogeny, and intra-land orogeny), resulting in the present geological tectonics framework (Lu et al. 2011).

During the early Paleozoic era, the Qilian Mountain region was a small ocean basin between the Tsaidam block and the North China block. The Caledonian movement in the late Silurian made the ancient ocean basin close, uplift and erode. In the Carboniferous, it began to sink and become a wide shallow-sea shelf or epicontinental sea. During the Triassic, South Qilian was still a sea basin, and marine sandstone-mudstone bearing limestone deposited. At the end of Late Triassic, influenced by Indosinian movement, Paleo-Tethys Ocean completely closed, with the whole Qilian Mountains uplifting to be a land, i.e., a denuded zone. Early Yanshan tectonic movements resulted in local tension of the Qilian Mountain areas. A series of inter- 
mountain faulted depression basins formed, and a suite of Jurassic age fluviolacustrine coal-bearing marsh facies and other clastic sediments were deposited. Cretaceous and Tertiary strata are mainly constituted by finegrained red clastic rocks and claystones. In the Quaternary, deposits mainly composed of glaciofluvial facies and glacial facies have been widely distributed in the basin (Fu and Zhou 1998).

The Qilian Mountain region, where permafrost conditions extend over the area of about $10^{5} \mathrm{~km}^{2}$ ( $\mathrm{Li}$ et al. 2012), is one of the regions with widespread permafrost. "Scientific Drilling Project of Gas Hydrate" in the Qilian mountain permafrost is located in Muli coalfield, Tianqun County, Qinghai Province of China (Fig. 1), where altitude is $4000 \sim 4300 \mathrm{~m}$, the mean annual

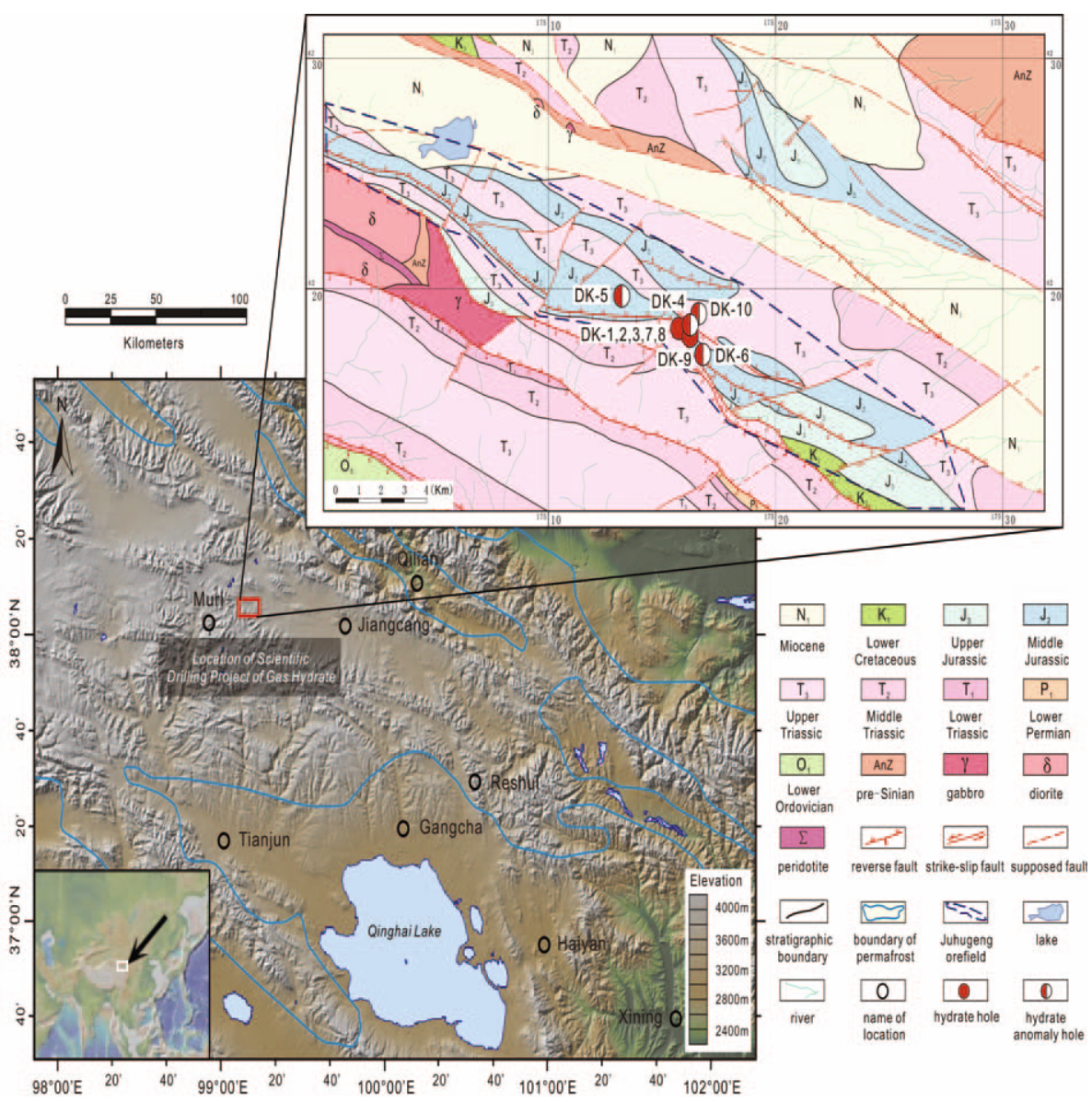

Fig. 1. The location of the Scientific Drilling Project of Gas Hydrate and the geological map for the study area in the Qilian Mountain permafrost (Ryan et al. 2009, Wang et al. 2014). 
ground surface temperature is about -2 to $-2.5^{\circ} \mathrm{C}$ ( $\mathrm{Wu}$ et al. 2010). The thickness of permafrost ranges from 60 to $95 \mathrm{~m}$, and in a considerable part of the region the permafrost thickness is greater than $100 \mathrm{~m}$ (Wu et al. 2010), severing as a favorable capping for gas hydrate. Except of Quaternary, Jurassic Jiangcang Formation $\left(J_{2} j\right)$ and Muli Formation $\left(J_{2} m\right)$ also expose in the study area. The two sets of strata contain multiple minable coal layers, whose coal layers occur at intervals of several to hundreds of meters below ground. The Jiangcang Formation is mainly composed of black and gray oily shale and mudstone with siltstone, fine sandstone, and middle sandstone. The Muli Formation mainly consists of gray siltstone, fine sandstone, middle sandstone, coarse sandstone, mixed with dark gray oily shale. The content of organic carbon in oily shale is $0.98 \sim 5.76 \%$ (Sun et al. 2014), which has achieved the standard of high-quality source rock. Oily shale has entered the post-mature phase and is a king of favorable gas source (Lu et al. 2013a, b).

\subsection{Geological characteristics of gas hydrate}

In total, ten scientific drilling wells for gas hydrate, namely DK-1, DK-2, DK-3, DK-4, DK-5, DK-6, DK-7, DK-8, DK-9, and DK-10, were completed in the study area (Fig. 1). Holes where gas hydrate samples were recovered include DK-1, DK-2, DK-3, DK-7, and DK-8, while in the holes of DK-4, DK-5, DK-6, DK-9, and DK-10, only anomalies indicating the likely existence of gas hydrate were discovered. Gas hydrate in the study area can accumulate in two forms. One form of gas hydrate is of thin-bedded, flaky, lumpy shape, and occurs in the fissures of siltstone, mudstone, and oily shale. Gas hydrate of this form observed by naked eyes is milky crystals with a thickness of several millimeters. Gas hydrate of the other form distributes in the pores of siltstone and fine sandstone, and cannot be identified by naked eyes, while an obvious low temperature anomaly can be identified by infrared camera.

In the winter of 2008, the DK-1 hole was mud-fluid drilled and intermittently cored with a wire line core barrel to $182.23 \mathrm{~m}$. In the summer of 2009 , three holes, DK-2, DK-3, and DK-4, were drilled with low temperature mudfluid and intermittently cored with a wire line core barrel and a splitting tube to target depths of 635.20, 765.01, and $466.65 \mathrm{~m}$, respectively (Fig. 2). The four wells in the lateral areas are distributed relatively close. The distance of hole DK-2 and hole DK-3 is the nearest, and the distance is only $10 \mathrm{~m}$. In the four wells, gas hydrate and its associated anomalies occur between about 115 and $396 \mathrm{~m}$, beneath the permafrost (Table 1). In addition, the thickness of permafrost is about $95 \sim 115 \mathrm{~m}$.

The combined information from drilling and core experiment studies shows that gas hydrates mainly occur in the Jiangcang Formation of Middle 


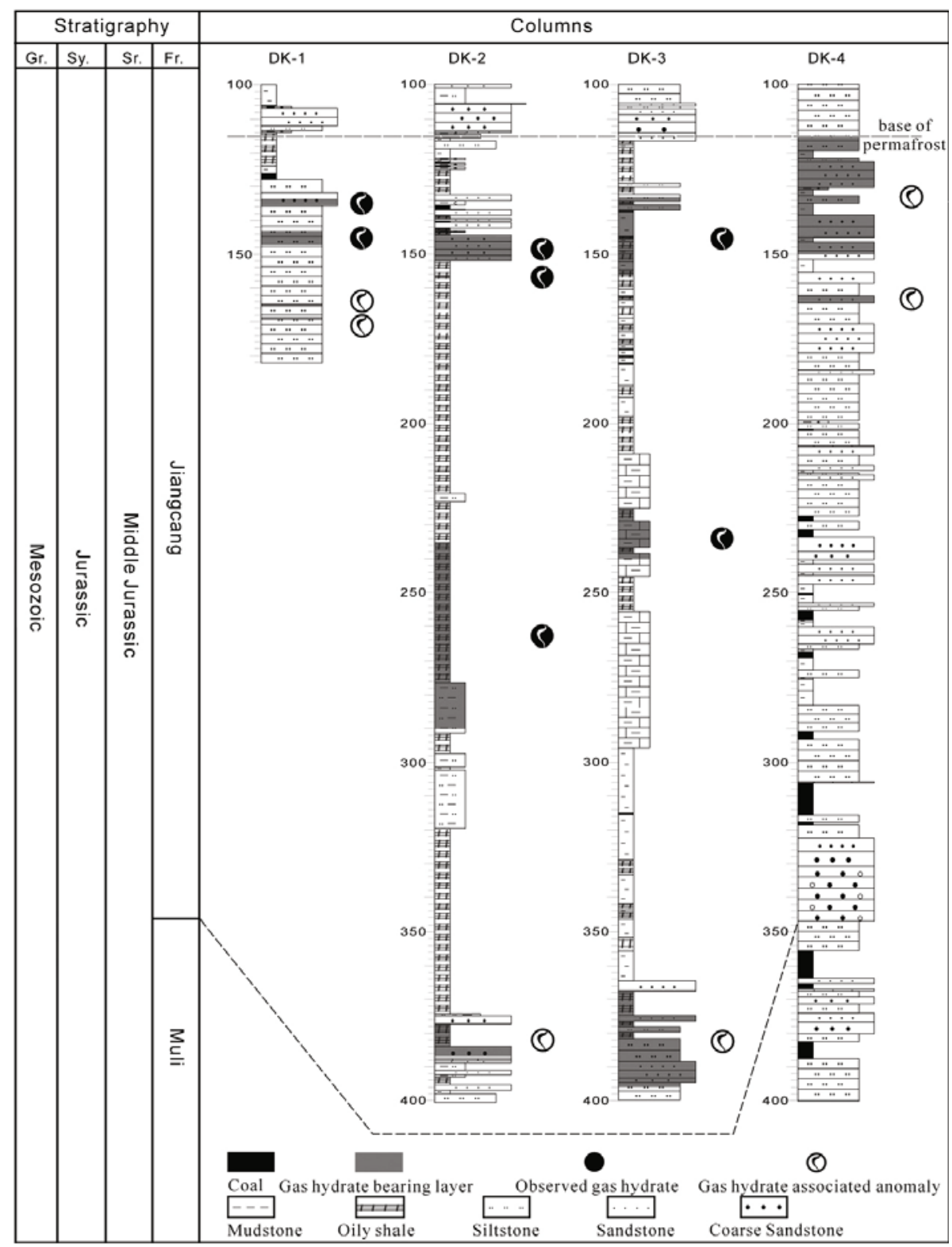

Fig. 2. Lithological columns of the DK-1 to DK-4 holes in Qilian Mountain permafrost (Lu et al. 2011).

Jurassic in the Muli permafrost. The porosity of the samples recovered from core data in the four wells ranges from 5 to $20 \%$, and the gas hydrate saturation ranges from 30 to $80 \%$ (Guo and Zhu 2011, Lin et al. 2013). The geo- 
Table 1

Gas hydrate drilling locations and its general characteristics (Lu et al. 2011)

\begin{tabular}{|c|c|c|c|c|c|c|c|}
\hline \multirow{2}{*}{ Holes } & \multicolumn{3}{|c|}{ Coordinates } & $\begin{array}{c}\text { Borehole } \\
\text { depth } \\
{[\mathrm{m}]}\end{array}$ & $\begin{array}{c}\text { Base } \\
\text { of perma } \\
{[\mathrm{m}]}\end{array}$ & $\begin{array}{c}\text { Top } \\
\text { of GH } \\
{[\mathrm{m}]}\end{array}$ & $\begin{array}{c}\text { Base } \\
\text { of GH } \\
{[\mathrm{m}]}\end{array}$ \\
\hline DK-1 & 4217899.114 & 33514986.723 & 4053.336 & 182.23 & 115 & 133.50 & 170.50 \\
DK-2 & 4217882.361 & 33514977.515 & 4053.460 & 635.20 & 115 & 144.40 & 387.50 \\
DK-3 & 4217894.413 & 33515000.925 & 4054.761 & 765.01 & $115 \sim 120$ & 133.00 & 396.00 \\
DK-4 & 4218130.803 & 33515164.170 & 4038.451 & 466.65 & $110 \sim 115$ & 115.00 & 163.00 \\
\hline
\end{tabular}

Note: GH indicates gas hydrate.

logical and occurrence characteristics indicate that gas hydrates occur in separate reservoirs below the base of permafrost. The reservoir type is considered by Boswell et al. (2011) and Koh et al. (2012) to be Type R-unique hydrate deposits within rocks. In addition, gas hydrates are distributed noncontinuously in the vertical direction in each borehole, and the law of gas hydrate distribution in the lateral areas between drill holes is not apparent due to the rock fracture system that plays an important role in gas hydrate distribution (Wang et al. 2014).

Specific geological characteristics of gas hydrate reservoir are summarized in Table 2. Compared to gas hydrate samples of the Mackenzie Delta of Canada, gas hydrate in the Qilian Mountain permafrost can be regarded as a new-type gas hydrate characterized by a relatively shallow bury depth, thin thickness of permafrost, complex gas components, and coal-bed methane gas source, which is of scientific, economic, and environmental significance (Zhu et al. 2010).

Table 2

Comparison of formation properties in the Qilian Mountain and Mackenzie Delta

\begin{tabular}{|c|c|c|}
\hline District & $\begin{array}{c}\text { Mackenzie Delta } \\
\text { (Bybee 2004, } \\
\text { Collett 2005) }\end{array}$ & $\begin{array}{l}\text { Qilian Mountain } \\
\text { (Zhu et al. 2010, } \\
\text { Lu et al. 2011) }\end{array}$ \\
\hline Gas component & $\mathrm{CH} 4$ & $\begin{array}{l}\mathrm{CH} 4, \mathrm{C} 2 \mathrm{H} 6, \mathrm{C} 3 \mathrm{H} 8, \\
\mathrm{C} 4 \mathrm{H} 10, \mathrm{CO} 2\end{array}$ \\
\hline Structure type & sI & sII \\
\hline Stratum & $\begin{array}{l}\text { Oligocene (Kugmallit, } \\
\text { Mackenzie Bay) }\end{array}$ & $\begin{array}{l}\text { Middle Jurassic } \\
\text { (Jiangcang) }\end{array}$ \\
\hline Reservoir lithology & Sandstone & $\begin{array}{l}\text { Oily shale, siltstone, } \\
\text { fine sandstone }\end{array}$ \\
\hline Permafrost & Arctic & Mountain \\
\hline Permafrost thickness & $640 \mathrm{~m}$ & $95 \mathrm{~m}$ \\
\hline Buried depth & $>1000 \mathrm{~m}$ & $133 \sim 396 \mathrm{~m}$ \\
\hline
\end{tabular}




\section{NUMERICAL SIMULATION METHODS}

The AMT numerical simulation contains two aspects, forward modeling and inversion. Methods for AMT forward modeling include finite difference method (FDM) (Mackie et al. 1994, Newman and Alumbaugh 1997), finite element method (FEM) (Wannamaker et al. 1987, De Lugão and Wannamaker 1996), and integral equation method (IEM) (Wannamaker 1991, Xiong and Trippz 1997). Two dimensional AMT forward modeling using FEM will bring some convenience in dealing with the inner boundary conditions which FDM and IEM fail to offer. What else, the coefficient matrix of FEM is positive definite, assuring the uniqueness of solution, so that FEM is an effective and universal method for forward problems. Inversion methods, which can be divided into direct inversion and indirect inversion, mainly include BOSTICK inversion, OCCAM inversion, RRI inversion, CG inversion, NLCG inversion, etc. (Goldberg and Rotstein 1982, Smith and Booker 1991, Constable et al. 1987, Hestenes 1973, Hestenes and Stiefel 1952, Rodi and Mackie 2001, Israil 2006, Spichak 2012). Among them, NLCG algorithm can avoid calculating the complete Jacobian matrix in each iteration and solving nonlinear equations of the whole model. This algorithm breaks out the framework of linear inversion, enhances the calculation efficiency, and is relatively stable in calculation. As a result, NLCG is an effective inversion method and widely applied to geophysical inversion (Newman and Alumbaugh 2000, Rodi and Mackie 2001, Hu et al. 2006). Based on the above analysis, in this paper we have chosen the FEM and NLCG algorithm to carry out the simulation. The followings are the basic AMT numerical simulation theories of the two algorithms.

\subsection{AMT forward modeling based on FEM}

According to Maxwell equations, steady-state electromagnetic field equations with angular frequency $\omega$ (time factor $e^{-i \omega t}$ ) write (Xu 1994):

$$
\begin{gathered}
\nabla \times \boldsymbol{E}=i \omega \mu \boldsymbol{H}, \\
\nabla \times \boldsymbol{H}=(\sigma-i \omega \varepsilon) \boldsymbol{E},
\end{gathered}
$$

where $\boldsymbol{E}$ is electric field intensity $[\mathrm{V} / \mathrm{m}], \boldsymbol{H}$ is magnetic field intensity $[\mathrm{A} / \mathrm{m}]$, $\omega, \mu, \sigma$, and $\varepsilon$ are angular frequency, magnetic permeability, electrical conductivity, and dielectric constant, respectively.

Let us assume the underground to be a two-dimensional electrical structure, $x$ axis and $y$ axis horizontal, $z$ axis vertical down, and $x$ axis parallel to the structural strike direction. When plane electromagnetic wave transmits to ground at any angle, the underground electromagnetic wave always travels downwards in the form of plane wave. At this time, Maxwell equations can 
be decomposed into two independent fields, TE polarization mode $\left(\boldsymbol{E}_{\boldsymbol{x}}, \boldsymbol{H}_{\boldsymbol{y}}\right.$, $\left.\boldsymbol{H}_{z}\right)$, and TM polarization mode $\left(\boldsymbol{H}_{\boldsymbol{x}}, \boldsymbol{E}_{\boldsymbol{y}}, \boldsymbol{E}_{z}\right)$. Expanding Eqs. 1 and 2 with consideration of $\partial / \partial x=0$, we can get two independent equation systems, which indicate TE mode and TM mode, respectively, with respect to $x$-component (Wannamaker et al. 1987).

TE polarization mode writes:

$$
\left\{\begin{array}{l}
\frac{\partial \boldsymbol{H}_{z}}{\partial y}-\frac{\partial \boldsymbol{H}_{y}}{\partial z}=(\sigma-i \omega \varepsilon) \boldsymbol{E}_{x} \\
\boldsymbol{H}_{y}=\frac{1}{i \omega \mu} \frac{\partial \boldsymbol{E}_{x}}{\partial z} \\
\boldsymbol{H}_{z}=-\frac{1}{i \omega \mu} \frac{\partial \boldsymbol{E}_{x}}{\partial y}
\end{array}\right.
$$

TM polarization mode writes:

$$
\left\{\begin{array}{l}
\frac{\partial \boldsymbol{E}_{z}}{\partial y}-\frac{\partial \boldsymbol{E}_{y}}{\partial z}=i \omega \mu \boldsymbol{H}_{x} \\
\boldsymbol{E}_{y}=\frac{1}{\sigma-i \omega \varepsilon} \frac{\partial \boldsymbol{H}_{x}}{\partial z} \\
\boldsymbol{E}_{z}=-\frac{1}{\sigma-i \omega \varepsilon} \frac{\partial \boldsymbol{H}_{x}}{\partial y}
\end{array}\right.
$$

From Eqs. 3 and $4, \boldsymbol{H}_{\boldsymbol{y}}, \boldsymbol{H}_{z}, \boldsymbol{E}_{\boldsymbol{y}}$, and $\boldsymbol{E}_{z}$ can be worked out. By substituting them into Eqs. 1 and 2, we get the partial difference equations for $\boldsymbol{E}_{\boldsymbol{x}}$ and $\mathbf{H}_{\mathbf{x}}$ :

$$
\begin{gathered}
\frac{\partial}{\partial y}\left(\frac{1}{i \omega \mu} \frac{\partial \boldsymbol{E}_{x}}{\partial y}\right)+\frac{\partial}{\partial z}\left(\frac{1}{i \omega \mu} \frac{\partial \boldsymbol{E}_{x}}{\partial z}\right)+(\sigma-i \omega \varepsilon) \boldsymbol{E}_{x}=0, \\
\frac{\partial}{\partial y}\left(\frac{1}{\sigma-i \omega \varepsilon} \frac{\partial \boldsymbol{H}_{x}}{\partial y}\right)+\frac{\partial}{\partial z}\left(\frac{1}{\sigma-i \omega \varepsilon} \frac{\partial \boldsymbol{H}_{x}}{\partial z}\right)+i \omega \mu \boldsymbol{H}_{x}=0 .
\end{gathered}
$$

Equations 5 and 6 can be uniformly expressed as:

$$
\nabla(\tau \nabla u)+\lambda u=0 .
$$

For the TE mode, we have

$$
u=\boldsymbol{E}_{x}, \quad \tau=\frac{1}{i \omega \mu}, \quad \lambda=\sigma-i \omega \varepsilon .
$$


For the TM mode, we have

$$
u=\boldsymbol{H}_{x}, \quad \tau=\frac{1}{\sigma-i \omega \varepsilon}, \quad \lambda=i \omega \mu .
$$

Considering boundary conditions, the variational problem equivalent to Eq. 7 writes:

$$
\left\{\begin{array}{l}
F(u)=\int_{\Omega}\left[\frac{1}{2} \tau(\nabla u)^{2}-\frac{1}{2} \lambda u^{2}\right] d \Omega+\int_{C D} \frac{1}{2} \tau k u^{2} d \Gamma \\
\left.u\right|_{A B}=1 \\
\delta F(u)=0
\end{array}\right.
$$

$\mathrm{AB}$ and $\mathrm{CD}$ are the upper boundary and lower boundary, respectively, in the $2 \mathrm{D}$ domain.

Solving AMT two-dimensional forwarding modeling problem with FEM in Eq. 10 (Coggon 1971, De Lugão and Wannamaker 1996), a complex coefficients equation can be obtained, writting

$$
K u=0 .
$$

By solving the above system of linear algebraic equations, the field value $u$ can be obtained, and $\boldsymbol{E}_{\boldsymbol{x}}$ in TE mode and $\boldsymbol{H}_{\boldsymbol{x}}$ in TM mode can be attained.

According to the definition of apparent resistivity, the TE and TM mode calculation equations are derived and expressed as:

$$
\begin{aligned}
& \rho_{T E}=\left.\frac{i}{\omega \mu}\left(\frac{\boldsymbol{E}_{\boldsymbol{x}}}{\boldsymbol{H}_{\boldsymbol{y}}}\right)^{2}\right|_{y=0}, \\
& \rho_{T M}=\left.\frac{i}{\omega \mu}\left(\frac{\boldsymbol{E}_{\boldsymbol{y}}}{\boldsymbol{H}_{\boldsymbol{x}}}\right)^{2}\right|_{y=0} .
\end{aligned}
$$

By substituting the second formula in Eq. 2 into Eq. 12, and letting $u=\boldsymbol{E}_{x}$, we have

$$
\rho_{T E}=-\left.i \omega \mu\left(u / \frac{\partial u}{\partial y}\right)^{2}\right|_{y=0} .
$$

By substituting the second formula in Eq. 4 into Eq. 13, and letting $u=\boldsymbol{H}_{x}$, we have 


$$
\rho_{T M}=\left.\frac{i}{\omega \mu \sigma^{2}}\left(\frac{\partial u}{\partial y} / u\right)^{2}\right|_{y=0}
$$

Through Eqs. 14 and 15, the apparent resistivity of the two polarization modes can be deduced, and electric stratification of the underground media can be judged intuitionally.

\subsection{AMT inversion based on NLCG}

Generally, the AMT inversion problem can be expressed as:

$$
\boldsymbol{d}=F(\boldsymbol{m})+\boldsymbol{e},
$$

where $\boldsymbol{d}=\left[d^{1}, d^{2}, \ldots, d^{N}\right]^{T}$ is the data vector, $d^{i}$ is the apparent resistivity or phase of impedance in TE mode or TM mode at a specific frequency point, $\boldsymbol{m}=\left[m^{1}, m^{2}, \ldots, m^{M}\right]^{T}$ is the model vector, $\boldsymbol{e}$ is the discrepancy vector, and $F$ is the response function of forward modeling. $m$ is set as model grid with $M$ elements, and each $M_{R}$ stands for the logarithmic resistivity of a specific grid. $\psi$ is defined as (Tikhonov and Arsenin 1978, Rodi and Mackie 2001):

$$
\psi(\boldsymbol{m})=(\boldsymbol{d}-F(\boldsymbol{m}))^{T} \boldsymbol{V}^{-1}(\boldsymbol{d}-\mathrm{F}(\boldsymbol{m}))+\lambda \boldsymbol{m}^{T} \boldsymbol{L}^{T} \boldsymbol{L} \boldsymbol{m} .
$$

If $\lambda, V$, and $L$ are given specific values, regularization factor $\lambda$ is a positive number. The positive definite matrix $\boldsymbol{V}$ and the discrepancy vector $\boldsymbol{e}$ are related in the form of covariation. $\boldsymbol{L}$ is a second order difference operator. When the model grid is unique, $\boldsymbol{L} \boldsymbol{m}$ can be approximated to be the Laplace operator of $\log \rho$. The $\lambda \boldsymbol{m}^{T} \boldsymbol{L}^{T} \boldsymbol{L} \boldsymbol{m}$ denotes a stable factor in the model space.

The gradient and Hesse matrix of objective function are defined as $\boldsymbol{g}(1 \times M)$ and $\boldsymbol{H}(H \times M)$, respectively. Define $\boldsymbol{A}$ as the Jacobian matrix of response function $F$, and we have

$$
\boldsymbol{A}^{i j}(\boldsymbol{m})=\partial_{j} F^{i}(\boldsymbol{m}), \quad i=1, \ldots, N, \quad j=1, \ldots, M .
$$

Substitute Eq. 18 into 17, and we get

$$
\begin{gathered}
\boldsymbol{g}(\boldsymbol{m})=-2 \boldsymbol{A}(\boldsymbol{m})^{T} \boldsymbol{V}^{-1}(\boldsymbol{d}-F(\boldsymbol{m}))+2 \lambda \boldsymbol{L}^{T} \boldsymbol{L} \boldsymbol{m}, \\
\boldsymbol{H}(\boldsymbol{m})=2 \boldsymbol{A}(\boldsymbol{m})^{T} \boldsymbol{V}^{-1} \boldsymbol{A}(\boldsymbol{m})+2 \lambda \boldsymbol{L}^{T} \boldsymbol{L}-2 \sum_{i=1}^{N} \boldsymbol{q}^{i} \boldsymbol{B}_{i}(\boldsymbol{m}),
\end{gathered}
$$

where $\boldsymbol{B}_{i}$ is the Hesse matrix of $F^{i}, \boldsymbol{q}=\boldsymbol{V}^{-1}(\boldsymbol{d}-F(\boldsymbol{m})), \boldsymbol{A}(\boldsymbol{m})^{T} \boldsymbol{V}^{-1}(\boldsymbol{d}-F(\boldsymbol{m}))$, and $\boldsymbol{A}(\boldsymbol{m})^{T} \boldsymbol{V}^{-1} \boldsymbol{A}(\boldsymbol{m})$ can be derived without calculating Jacobian matrix $\boldsymbol{A}$. 
Using NLCG algorithm, we can directly solve the minimization problem. NLCG by Polak-Ribiere is introduced to calculate the minimum value of Eq. 17, with detail process as follows:

$$
\begin{gathered}
\boldsymbol{m}_{0}=\boldsymbol{m}_{\mathrm{given}}, \\
\psi\left(\boldsymbol{m}_{k}+\alpha_{k} \boldsymbol{p}_{k}\right)=\min \psi\left(\boldsymbol{m}_{k}+\alpha \boldsymbol{p}_{k}\right), \quad \boldsymbol{m}_{k+1}=\boldsymbol{m}_{k}+\alpha_{k} \boldsymbol{p}_{k}, \quad k=0,1,2, \\
\alpha_{k, j+1}=\alpha_{k, j}-\frac{\boldsymbol{g}_{k, j}^{T} \boldsymbol{p}_{k}}{\boldsymbol{p}_{k}^{T} \tilde{\boldsymbol{H}}_{k, j} \boldsymbol{p}_{k}},
\end{gathered}
$$

where $\boldsymbol{m}_{\text {given }}$ is the vector sequence of a known initial model. By calculating the searching step $\alpha_{k}$ along the searching direction $\boldsymbol{p}_{k}$, the objective function of minimization can be iterated. The iterations along the searching direction are as follows:

$$
\begin{gathered}
\boldsymbol{p}_{0}=-\boldsymbol{C}_{0} \boldsymbol{g}_{0}, \\
\boldsymbol{p}_{k}=-\boldsymbol{C}_{k} \boldsymbol{g}_{k}+\beta_{k} p_{k-1}, \quad k=1,2,
\end{gathered}
$$

where, $\boldsymbol{g}_{k}$ denotes the gradient of $\psi$ when $m=m_{k}, C_{k}$ is the precondition factor, $\beta_{k}$ is the weighting factor of conjugate direction vector. There are many expression approaches of $\beta_{k}$, and a different expression approach stands for different conjugate gradient method. This paper adopts the PRP (PolakRibiere-Polyak) nonlinear conjugate gradient algorithm to calculate $\beta_{k}$ :

$$
\beta_{k}=\frac{\boldsymbol{g}_{k}^{T} \boldsymbol{C}_{k}\left(\boldsymbol{g}_{k}-\boldsymbol{g}_{k-1}\right)}{\boldsymbol{g}_{k-1}^{T} \boldsymbol{C}_{k-1} \boldsymbol{g}_{k-1}} .
$$

It is not necessary to conjugate the searching direction with any certain fixed matrices, but the following condition should be fulfilled:

$$
\boldsymbol{p}_{k}^{T}\left(\boldsymbol{g}_{k}-\boldsymbol{g}_{k-1}\right)=0, \quad k>0 .
$$

The Gauss-Newton iteration is adopted to solve the problem, and cubic difference is adopted to calculate $\alpha_{k, j+1}$. Following the secondary iteration, the optimized $\alpha$ will be obtained firstly, and then it is substituted to the minimum functional iteration to calculate the model variation. The iteration will not stop until the termination condition is fulfilled or the iteration achieves the termination number, when the best fit model is obtained. 


\section{GEOELECTRICAL MODEL FOR THE STUDY AREA}

To carry out AMT numerical simulation for gas hydrate in the Qilian Mountain permafrost, it is necessary to set appropriate resistivity value for gas hydrate reservoirs based on the occurrence of gas hydrate in the study area, and establishing an actual geoelectrical model to simulate the variation characteristics is a must. The physical parameters that affect the electrical property consist of porosity and saturation of the gas hydrate, so that Archie equation, usually used in the reservoir evaluation, can be applied to the gas hydrate assessment, writing (Archie 1942):

$$
R_{t}=\frac{a R_{w}}{\phi^{m} S_{w}^{n}},
$$

where $R_{t}$ is the resistivity value in the formation, $R_{w}$ is the resistivity value of formation water, $\phi$ indicates the porosity, and $S_{w}$ denotes the water saturation of the pores in the formation. Parameters $a, m$, and $n$ are empirical indices, which can be determined by the actual stratum, and $1.5<m<3$, $0.5<a<2.5$.

According to the previous research for gas hydrate reservoirs (Lee and Collett 2011, Guo and Zhu 2011), it can be determined that $R_{w}=2 \Omega . \mathrm{m}$, $n=1.9386, a=0.5$, and $m=1.32$, so that Eq. 25 can be transformed to be

$$
R_{t}=\frac{1.02}{\phi^{1.32}\left(1-S_{h}\right)^{1.9386}} \text {. }
$$

It can be seen from Eq. 26 that the resistivity of gas hydrate reservoir is a function of porosity and saturation of gas hydrate. Here Eq. 26 is defined to be the resistivity calculation model for the gas hydrate reservoir. Therefore, according to the porosity and saturation of the gas hydrate reservoir in the study area, the reservoir resistivity can be deduced.

The application of AMT method is conditioned on the resistivity difference of the target reservoir and surrounding rock. AMT sounding can reflect the electrical property of formation owing to its wide frequency range, and then, using related inversion technique, the geological information of the target reservoirs can be acquired. Therefore, to simulate the gas hydrate in the Qilian Mountain permafrost with AMT method, the resistivity value of gas hydrate and surrounding rock should be determined first. Gas hydrates at normal temperatures and pressures are very unstable and easy to decompose, making it impossible to measure resistivity value with conventional samples. However, it is a direct and effective method to analyze the resistivity of the gas hydrate reservoir and surrounding rock using the in situ log results. So the well log data of DK-1 and DK-3 holes where gas hydrate was recovered in the Qilian Mountain permafrost is used to analyze formation electrical characteristics of the study area (Fig. 3). 

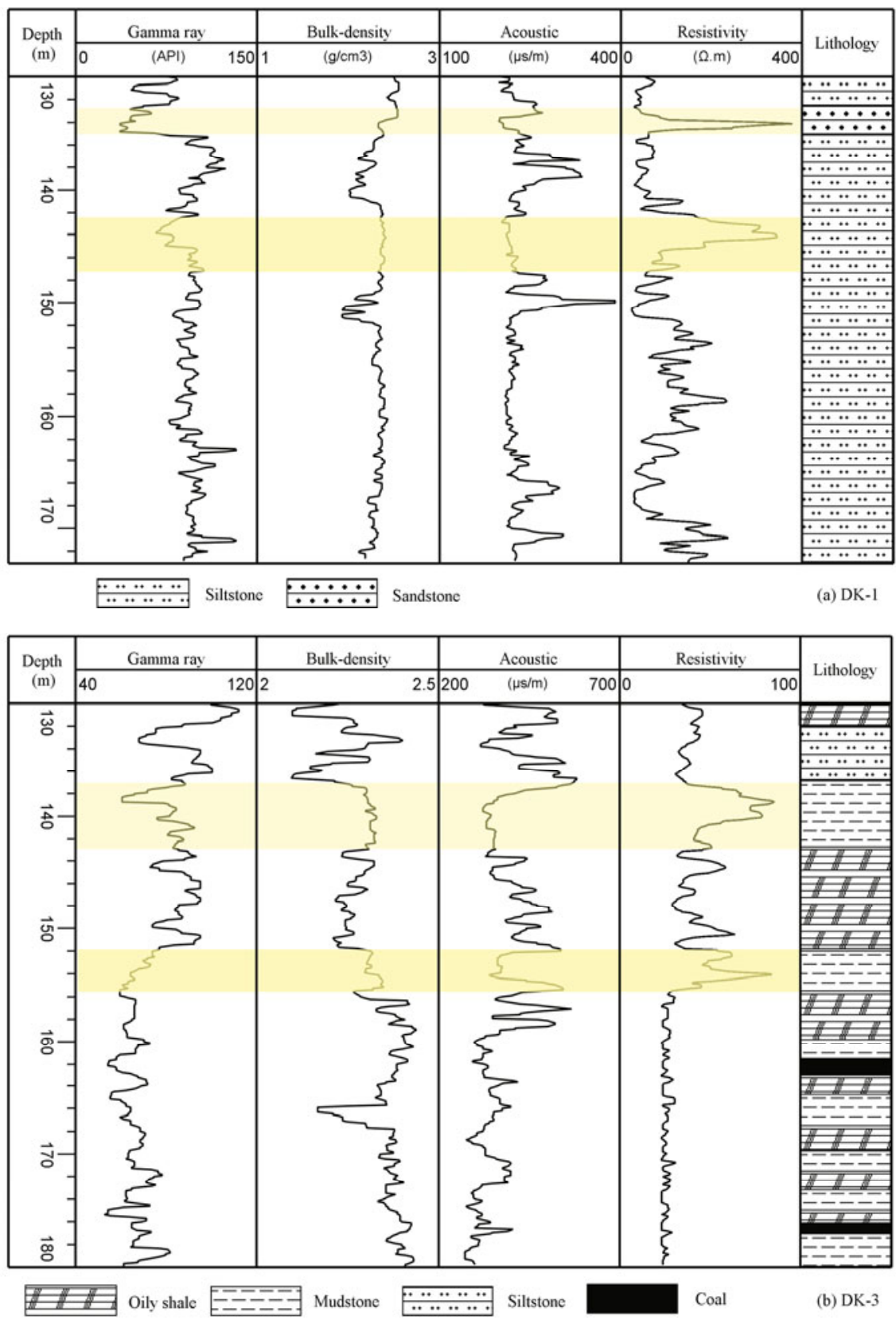

Fig. 3. Downhole logs from gas hydrate scientific drilling holes in the Qilian Mountain permafrost (Lu et al. 2011, Guo and Zhu 2011). Data shown include the natural gamma ray log, bulk-density, acoustic, and electrical resistivity data. Yellow bands indicate the gas hydrate bearing layers. 
Gas hydrate occurrences are supported by macroscopically highresistivity and acoustic velocity in the well log profiles (Carcione and Gei 2004, Lee and Collett 2011). It is very clear that the resistivity and velocity of the gas hydrate bearing layer are relatively higher than the surrounding rock in the holes of DK-1 and DK-3 (Fig. 3). Although the coal layer has a relatively high signal of resistivity, its velocity signals are relatively low. Hence, four intervals (133.5 135.5, 142.9 147.7, 137.4 143.3, and $152 \sim 155.5 \mathrm{~m}$ ) are interpreted as gas hydrate bearing layers from the comprehensive well $\log$ data, where resistivity and velocity are relatively high and natural gamma ray and density are relatively low. These well log data interpretations are supported by field observations of gas hydrate occurrences and associated anomalies.

The high-resistivity anomaly tends to be more distinct along with the increase of the thickness of gas hydrate bearing layer. By statistically classifying the resistivity value of gas hydrate bearing layers in terms of lithological characteristics (Table 3), we can see that the gas hydrate revealed by the hole of DK-1 exists in sandstone and siltstone (Fig. 3a), and the average resistivity value of gas hydrate bearing layers is 2.97 times higher than that of the surrounding rock. The gas hydrate revealed by DK-3 hole exists in mudstone (Fig. 3b), and the average resistivity value of gas hydrate bearing layers is 2.96 times higher than that of the surrounding rock.

Table 3

Statistics of the values of resistivity logging in gas hydrate reservoirs

\begin{tabular}{|c|c|l|c|c|}
\hline Borehole & $\begin{array}{c}\text { Gas hydrate } \\
\text { bearing layers } \\
{[\mathrm{m}]}\end{array}$ & $\begin{array}{c}\text { Reservoir } \\
\text { lithology }\end{array}$ & $\begin{array}{c}\text { Resistivity value } \\
\text { of reservoir } \\
{[\Omega . \mathrm{m}]}\end{array}$ & $\begin{array}{c}\text { Resistivity value } \\
\text { of surrounding rock } \\
{[\Omega . \mathrm{m}]}\end{array}$ \\
\hline DK-1 & $133.5 \sim 135.5$ & Sandstone & $113.97 \sim 378.41$ & $50.99 \sim 98.10$ \\
$142.9 \sim 147.7$ & Siltstone & $287.85 \sim 349.92$ & $37.7 \sim 168.32$ \\
\hline DK-3 & $137.4 \sim 143.3$ & Mudstone & $52.95 \sim 83.36$ & $25.12 \sim 28.13$ \\
\hline
\end{tabular}

Based on the electrical characteristics of reservoirs with different lithology, the resistivity value of the gas hydrate reservoir in the geoelectrical model is set to be 3 times higher than that of the surrounding rock. According to the resistivity variation characteristics of the permafrost in the study area, the resistivity value of the permafrost layer is set to be 2 times higher than the resistivity value of the gas hydrate reservoir (Zhu et al. 2010, Lin et al. 2013). In accordance with resistivity calculation model, by setting differ- 
ent porosities and saturation of the gas hydrate reservoir, different geoelectrical models can be established with the above electrical relationships to lay a foundation for AMT numerical simulation.

\section{RESULTS AND DISCUSSION}

\subsection{Response characteristics of high-resistance abnormal body of gas hydrate}

As gas hydrate in the Qilian Mountain permafrost occurs abnormally in the local scope, the gas hydrate reservoir can be modeled as high-resistance abnormal body. To determine gas hydrate reservoirs favorable to AMT prospecting in the study area, the response characteristics of AMT forward modeling for high-resistance abnormal body of gas hydrate are analyzed with variation of resistivity, occurrence scale, and bury depth. Based on the occurrences variation of gas hydrate, different geoelectrical models are designed, of which: the first layer is the permafrost layer with resistivity $2 \rho$, thickness $100 \mathrm{~m}$ (Zhu et al. 2010, Lu et al. 2011, Pang et al. 2013); the second layer is the gas hydrate reservoir, while surrounding rock resistivity is $1 / 3 \rho$, and a distance of $h$ below the permafrost layer there is a highresistance abnormal body of gas hydrate with resistivity $\rho$, and $d \times 200 \mathrm{~m}$ of size (Fig. 4).

Because gas hydrate samples recovered from the study area have been shallow buried and had a high resistivity (Lu et al. 2011, Zhu et al. 2010), and the earth's surface is covered by high-resistivity permafrost, parameters for forward modeling are set as follows: frequencies range from 0.1 to $10000 \mathrm{~Hz}$ with detail frequencies shown in Table 4. Note that the length of profile line is $5 \mathrm{~km}$ and the station spacing is $25 \mathrm{~m}$.

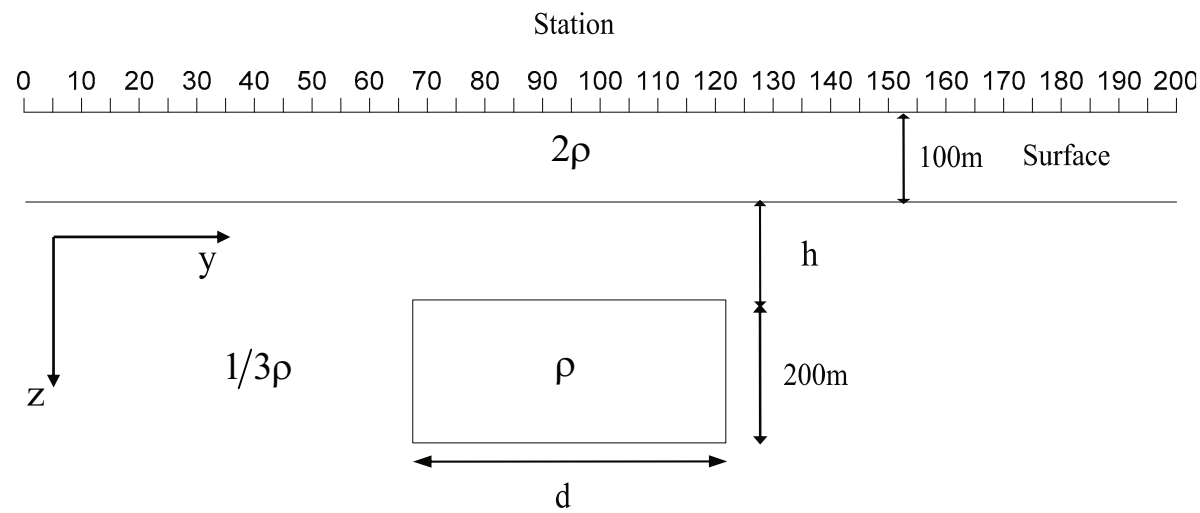

Fig. 4. The geoelectrical model of high-resistance abnormal body of gas hydrate. 
Frequency points for AMT forward modeling

\begin{tabular}{|c|l|}
\hline Count & \multicolumn{1}{|c|}{ Frequency point $[\mathrm{Hz}]$} \\
\hline \multirow{5}{*}{91} & $8577,7365,6310,5412,4642,3981,3415,2929,2512,2154,1848,1585$, \\
& $1359,1166,1000,858,736,631,541,464,398,341,293,251,215,185$, \\
& $\begin{array}{l}158,136,117,100,85.8,73.6,63.1,54.1,46.4,39.8,34.1,29.3,25.1, \\
\\
\end{array}$ \\
& $2.93,2.51,2.15,1.85,1.59,1.36,1.17,1.00,0.858,0.736,0.631,0.541$, \\
\hline
\end{tabular}

\subsubsection{Forward modeling of different resistivities}

To study the influence of resistivity on AMT response characteristics of gas hydrate in the Qilian Mountain permafrost, different resistivities are assumed based on the porosity and saturation of gas hydrate. Based on the actual data, the porosity of the high-resistance abnormal body of gas hydrate is set to be $10 \%$, and the saturations are assumed to be $30,40,50,60,70$, and $80 \%$, corresponding to $43,57,82,126,220$, and $483 \Omega . m$ of resistivity with an average value of $168.5 \Omega$.m. These values can be derived according to the resistivity model. By fixing depth $h=100 \mathrm{~m}$ and width $d=500 \mathrm{~m}$, and changing $\rho$, whose values are 43,168 , and $483 \Omega . \mathrm{m}$, the apparent resistivity section diagrams of TE and TM modes by AMT forward modeling with FEM can be obtained, as shown in Fig. 5.

From Figure 5, we can see that there are different levels of concaves in the apparent resistivity contour, meaning the high-resistivity anomaly appears, and indicating the existence of gas hydrate. So simulation of the high resistance abnormal body of gas hydrate in the surrounding rock with lower resistivity is effective. In the section diagrams of apparent resistivity in $\mathrm{TE}$ mode, the high-resistance abnormal body of gas hydrate can be well distinguished longitudinally, and electrical influence scope of the high-resistivity anomaly can be delineated in the longitudinal direction. The TM mode apparent resistivity can well distinguish anomalies in the horizontal direction, and delineate the horizontal electrical influence scope of the high resistance abnormal body of gas hydrate.

When the resistivity of gas hydrate reservoir reaches $43 \Omega . \mathrm{m}$ (Fig. 5a), there will be a high-resistivity anomaly at the top around $100 \mathrm{~Hz}$ in $\mathrm{TE}$ mode, with a wide influence scope ranging from 0.4 to $100 \mathrm{~Hz}$. The highresistivity anomaly in TM mode ranges from 2250 to $2750 \mathrm{~m}$, with a width of $500 \mathrm{~m}$, which shows good compatibility with the actual scope of highresistance abnormal body. When the resistivity reaches $168 \Omega . m$ (Fig. 5b), a high-resistivity anomaly appears at the top of $300 \mathrm{~Hz}$ in TE mode, and the 


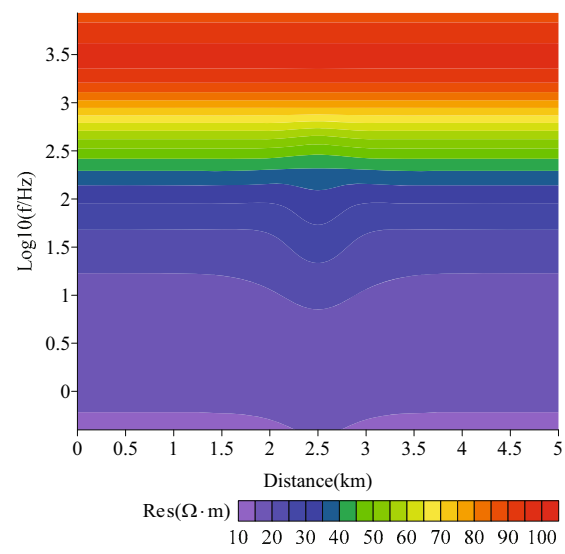

(a) TE mode $(\rho=43 \Omega . \mathrm{m})$

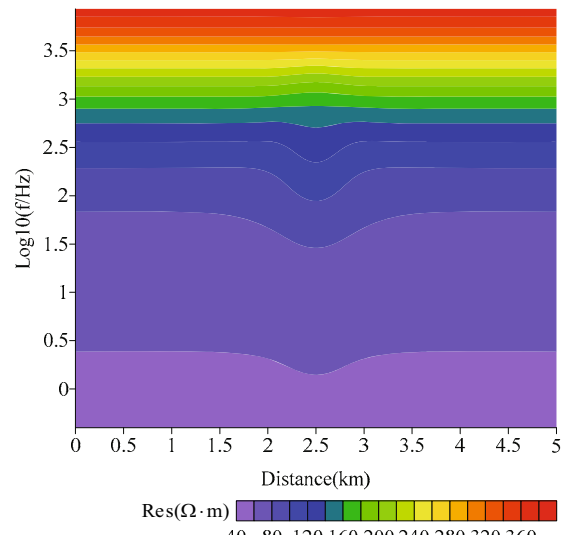

(b) TE mode $(\rho=168 \Omega$ m)

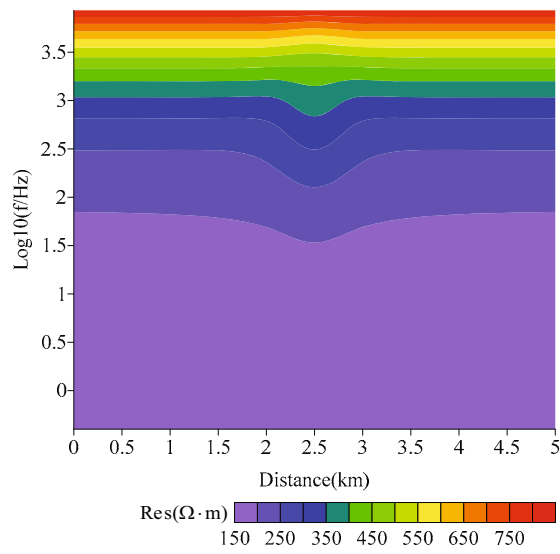

(c) TE mode $(\rho=483 \Omega . \mathrm{m})$

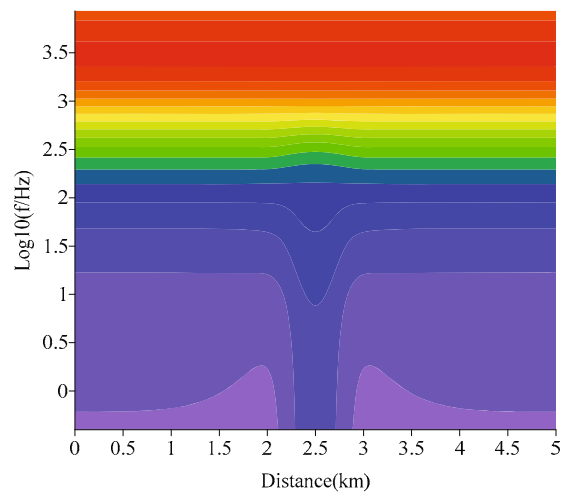

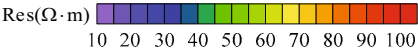

TM mode $(\rho=43 \Omega . \mathrm{m})$

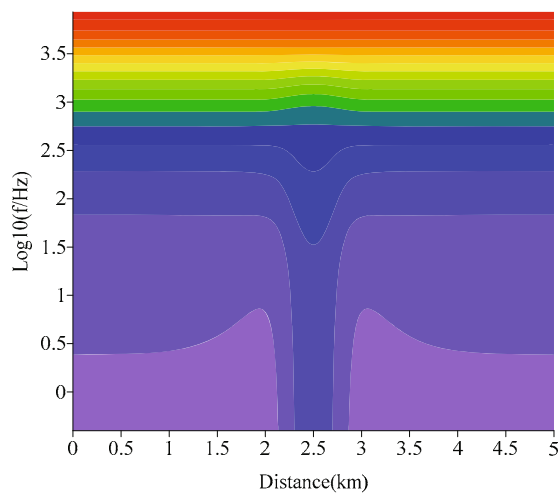

$\operatorname{Res}(\Omega \cdot \mathrm{m})$

4080120160200240280320360

TM mode $(\rho=168 \Omega . \mathrm{m})$

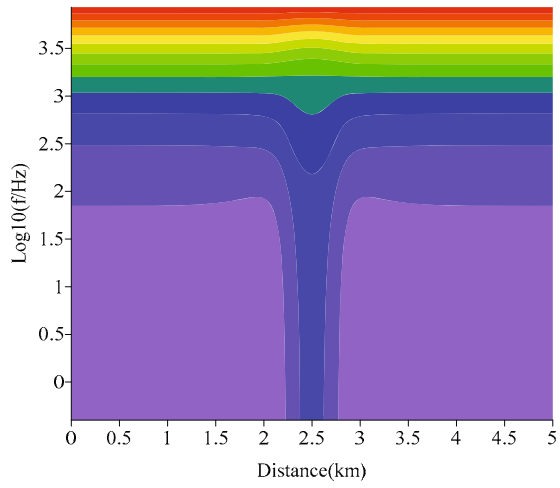

$\operatorname{Res}(\Omega \cdot \mathrm{m})$

$\begin{array}{llllllll}150 & 250 & 350 & 450 & 550 & 650 & 750\end{array}$

TM mode $(\rho=483 \Omega . \mathrm{m})$

Fig. 5. The apparent resistivity section diagrams of the high-resistance abnormal body of gas hydrate with different resistivities. 
influential frequency range reduces to $3 \sim 300 \mathrm{~Hz}$. The horizontal influence scopes of the high-resistivity anomaly in TM mode are similar when the resistivity is 43 and $168 \Omega$.m, meaning the results in TM mode can reflect the actual condition. When the resistivity for gas hydrate reservoir is $483 \Omega . \mathrm{m}$ (Fig. 5c), the high-resistivity anomaly appears around $1000 \mathrm{~Hz}$ in TE mode, and the frequency range reduces further, mainly from 100 to $1000 \mathrm{~Hz}$; the horizontal influence scope of the high-resistivity anomaly in TM mode ranges from 2350 to $260 \mathrm{~m}$, with a width of $300 \mathrm{~m}$, which differs largely from the actual condition.

It can be seen from the above analysis that when the bury depth and occurrence scale of gas hydrate reservoir are fixed, with the increase of resistivity, the influence scopes of the high-resistivity anomaly in TE and TM modes decrease, and response characteristics of AMT forward modeling weaken, indicating that the formation with high resistivity in the study area will not benefit to the identification and delineation of gas hydrate reservoir with AMT sounding.

When the resistivity of the high-resistance abnormal body of gas hydrate is $483 \Omega . \mathrm{m}$, the response characteristics of forward modeling will deviate from the actual condition largely, indicating that AMT method cannot prospect the gas hydrate reservoirs when the resistivity of the reservoir is higher than $483 \Omega . m$. According to the porosity and saturation of the gas hydrate in the Qilian Mountain permafrost, resistivities of the reservoirs can be estimated with Eq. 26 (Table 5). From Table 3 we can see that when the resistivity

Table 5

The resistivity values of gas hydrate model under different reservoir conditions

\begin{tabular}{|c|c|c|c||c|c|c|c|}
\hline \multirow{2}{*}{$\begin{array}{c}\text { Gas } \\
\text { hydrate } \\
\text { model }\end{array}$} & \multicolumn{2}{|c||}{ Reservoir condition } & \multirow{2}{*}{\begin{tabular}{c} 
Resistivity \\
\cline { 5 - 6 }
\end{tabular}} & $\begin{array}{c}\text { Gas } \\
\text { hydrate } \\
{[\%]}\end{array}$ & $\begin{array}{c}S h \\
{[\%]}\end{array}$ & {$[\Omega . \mathrm{m}]$} & \multicolumn{2}{|c|}{ Reservoir condition } & \multirow{2}{*}{$\begin{array}{c}\text { Resistivity } \\
\text { model }\end{array}$} & $\begin{array}{c}\phi \\
{[\%]}\end{array}$ & $\begin{array}{c}S h \\
{[\%]}\end{array}$ & {$[\Omega . \mathrm{m}]$} \\
\hline 1 & 5 & 30 & 106 & 13 & 15 & 30 & 25 \\
2 & 5 & 40 & 143 & 14 & 15 & 40 & 34 \\
3 & 5 & 50 & 204 & 15 & 15 & 50 & 48 \\
4 & 5 & 60 & 314 & 16 & 15 & 60 & 74 \\
5 & 5 & 70 & 549 & 17 & 15 & 70 & 129 \\
6 & 5 & 80 & 1205 & 18 & 15 & 80 & 283 \\
7 & 10 & 30 & 43 & 19 & 20 & 30 & 17 \\
8 & 10 & 40 & 57 & 20 & 20 & 40 & 23 \\
9 & 10 & 50 & 82 & 21 & 20 & 50 & 33 \\
10 & 10 & 60 & 126 & 22 & 20 & 60 & 50 \\
11 & 10 & 70 & 220 & 23 & 20 & 70 & 88 \\
12 & 10 & 80 & 483 & 24 & 20 & 80 & 193 \\
\hline
\end{tabular}


of gas hydrate reservoir is higher than $483 \Omega . \mathrm{m}$, the corresponding porosity will be less than $5 \%$, and saturation will be higher than $70 \%$, indicating that the reservoirs are of low porosity and high saturation.

From the above analysis it follows that for gas hydrate reservoirs in the Qilian Mountain permafrost, when the porosity is less than $5 \%$, saturation is higher than $70 \%$, the AMT method cannot identify and delineate gas hydrate reservoirs.

\subsubsection{Forward modeling of occurrence scales}

To reflect the general electrical properties of gas hydrate reservoirs in the Qilian Mountain permafrost, the average resistivity derived from the conditions that porosity is assumed to be $10 \%$ and saturation is assumed to be $30 \sim 80 \%$ is set as $\rho$ for the high resistance abnormal body of gas hydrate. $\rho$ is set to be $168 \Omega . \mathrm{m}$. The upper boundary is $100 \mathrm{~m}$ far from the permafrost layer. The width of the high-resistance abnormal body is set to be 50,350, and $400 \mathrm{~m}$. Other parameters for the forward simulation are the same as the above-mentioned values. So, after AMT forward simulation with FEM, the apparent resistivity section diagrams can be obtained, as illustrated in Fig. 6 .

From Figure 6, it can be seen that with the increase of the width of the high-resistance abnormal body from 50 to $400 \mathrm{~m}$, influence scopes of the high-resistivity anomaly in TE and TM modes are increasing, and the response characteristics of AMT forward modeling are strengthening. When the width of the high-resistance abnormal body is $50 \mathrm{~m}$ (Fig. 6a), the contour of apparent resistivity in TE mode expands horizontally, i.e., no response characteristic occurs. There is also no response characteristic of the highresistivity anomaly in the horizontal direction in TM mode, indicating that the contour cannot reflect the distribution of anomalies. When the width of the high-resistance abnormal body is $350 \mathrm{~m}$ (Fig. 6b), the contour of apparent resistivity concaves downward distinctly, and the anomaly appears at the top around $300 \mathrm{~Hz}$, with frequencies ranging from 3 to $300 \mathrm{~Hz}$. In the TM mode, the high-resistivity anomaly distributes from 2350 to $2650 \mathrm{~m}$, with a width of $300 \mathrm{~m}$, which is not totally consistent with the high-resistance abnormal body. When the width of the high-resistance abnormal body is $400 \mathrm{~m}$ (Fig. 6c), a more distinct downward concave appears in the contour of TE mode, and AMT response characteristics are also strengthen. In the TM mode, the high-resistivity anomaly distributes from 2300 to $2700 \mathrm{~m}$, with a width of $400 \mathrm{~m}$, which coincides well with the actual high-resistance abnormal body of gas hydrate.

From the above analysis it follows that for the high-resistance abnormal body of gas hydrate in the Qilian Mountain permafrost, when the resistivity and bury depth are fixed at certain values, with the increase of occurrence scale of the abnormal body, influence scopes of high-resistivity anomalies 


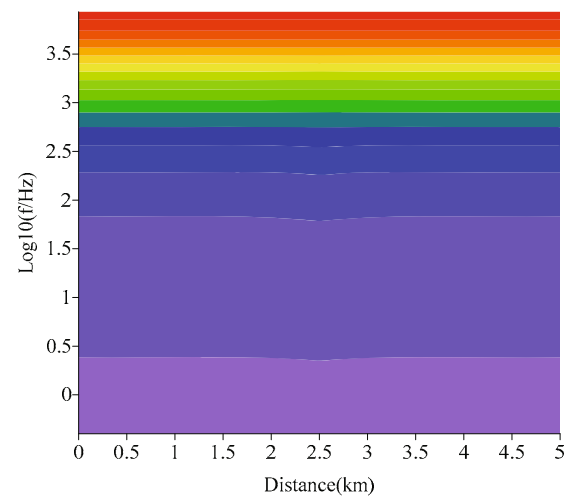

$\operatorname{Res}(\Omega \cdot \mathrm{m})$

$40 \quad 80120160200240280320360$

(a)

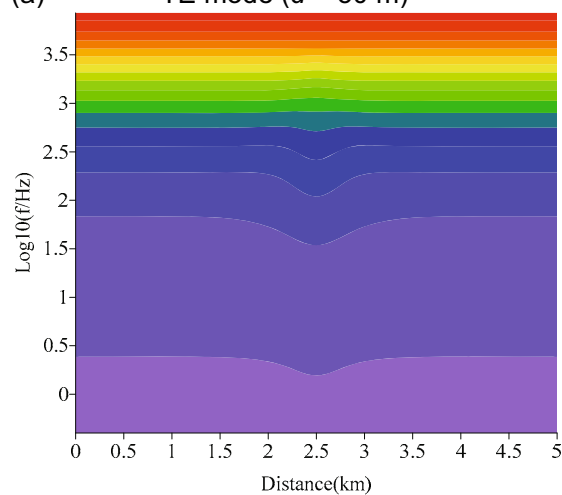

$\operatorname{Res}(\Omega \cdot \mathrm{m})$

$40 \quad 80120160200240280320360$

(b) TE mode $(d=350 \mathrm{~m})$

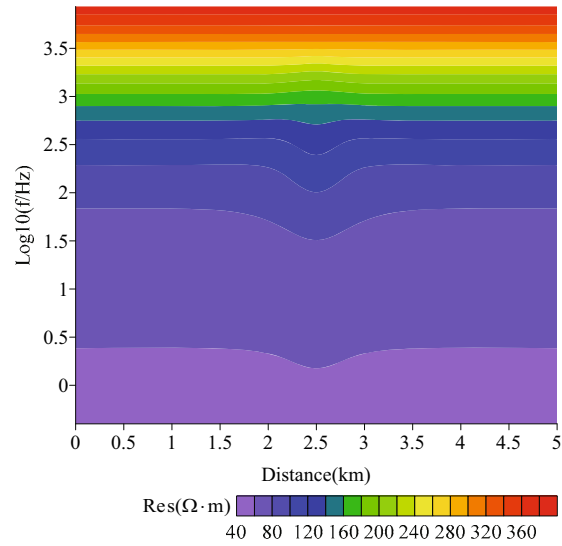

(c)

TE mode $(d=400 \mathrm{~m})$

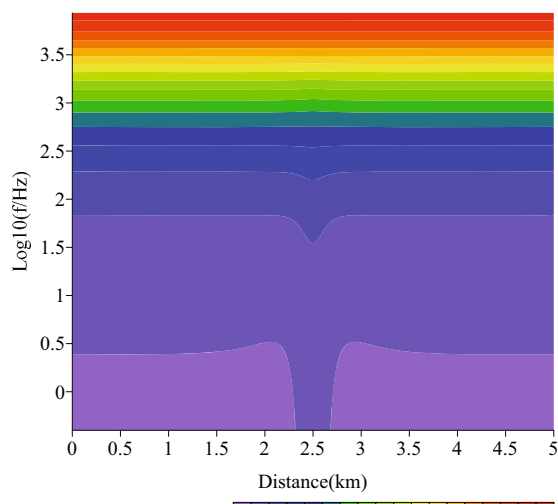

$\operatorname{Res}(\Omega \cdot \mathrm{m})$

$40 \quad 80120160200240280320360$

TM mode $(d=50 \mathrm{~m})$

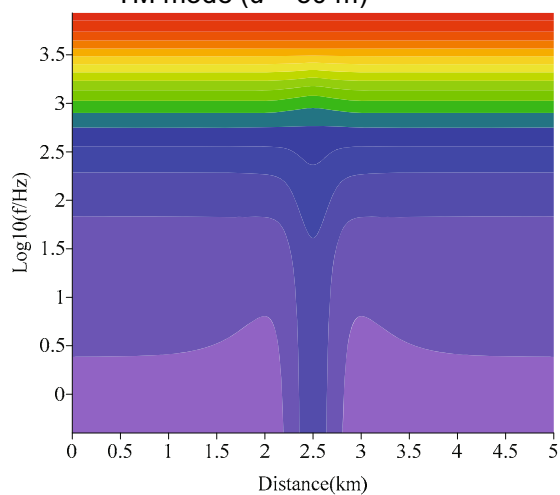

$\operatorname{Res}(\Omega \cdot \mathrm{m})$

$40 \quad 80120160200240280320360$

TM mode $(d=350 \mathrm{~m})$

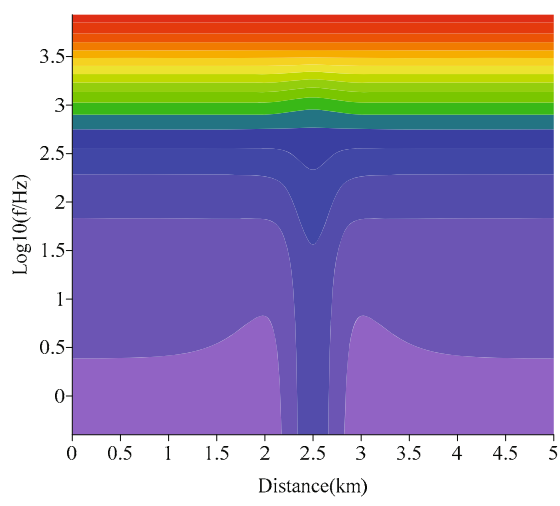

$\operatorname{Res}(\Omega \cdot \mathrm{m})$

$40 \quad 80120160200240280320360$

TM mode $(d=400 \mathrm{~m})$

Fig. 6. The apparent resistivity section diagrams of the high-resistance abnormal bodv of gas hvdrate with different occurrence scales. 
illustrated in the apparent resistivity section diagrams increase, and the response characteristics of AMT forward modeling strengthen. When the occurrence scale of the gas hydrate reservoir is less than $50 \mathrm{~m}$, the AMT method cannot identify it, while when the occurrence scale is larger than $400 \mathrm{~m}$, the AMT method can identify and delineate the reservoir.

\subsubsection{Forward modeling of different depths}

To study the influence of gas hydrate reservoir bury depth on AMT response characteristics, $\rho$ is fixed to be $168 \Omega . \mathrm{m}$, and width is fixed to be $400 \mathrm{~m}$ $(d=400 \mathrm{~m})$. The distances between upper boundary of the abnormal body and the permafrost layer, $h$, are set to be 100,350 , and $400 \mathrm{~m}$, respectively. The other parameters are the same as the above-mentioned values. After AMT forward simulation with FEM, the apparent resistivity section diagrams can be obtained, as illustrated in Fig. 7.

From Figure 7 it follows that, when the bury depth increases from 200 to $500 \mathrm{~m}$, the influence scope of apparent resistivity in TE and TM modes decreases, and the AMT forward modeling response characteristics weaken. When the bury depth of the high-resistance abnormal body is $200 \mathrm{~m}$ (Fig. 7a), the contour of apparent resistivity in TE mode concaves downwards distinctly, and the high-resistivity anomaly appears at the top around $300 \mathrm{~Hz}$ with frequencies ranging from 3 to $300 \mathrm{~Hz}$. In the TM mode, the high-resistivity anomaly ranges from 2300 to $2700 \mathrm{~m}$, with a width of $400 \mathrm{~m}$ which shows good compatibility with the actual conditions. When the bury depth of the high-resistance abnormal body is $450 \mathrm{~m}$ (Fig. 7b), the bending degree of the apparent resistivity contour in TE mode gets weak distinctly, and the AMT response characteristics also weaken. There is no horizontal response in the contour of apparent resistivity in TM mode, meaning the contour cannot reflect the distribution of anomalies. When the bury depth of the high-resistance abnormal body is $500 \mathrm{~m}$ (Fig. 7c), the contour of apparent resistivity in TE mode expands horizontally, i.e., no response characteristic occurs. No response characteristic occurs in TM mode, indicating that the contour cannot reflect the distribution of anomalies.

From the above analysis it follows that, for the high-resistance abnormal body of gas hydrate in the Qilian Mountain permafrost, when the resistivity and occurrence scale are fixed to certain values, with the increase of bury depth of the abnormal body, apparent resistivity influence scopes in both TE and TM modes decrease, and the response characteristics of AMT forward modeling weaken. When the bury depth of the gas hydrate reservoir is higher than $500 \mathrm{~m}$, AMT method cannot identify and delineate the reservoir.

Based on the measured gas components of gas hydrate, combined with the data of the mean annual ground temperature, temperature gradient, and 


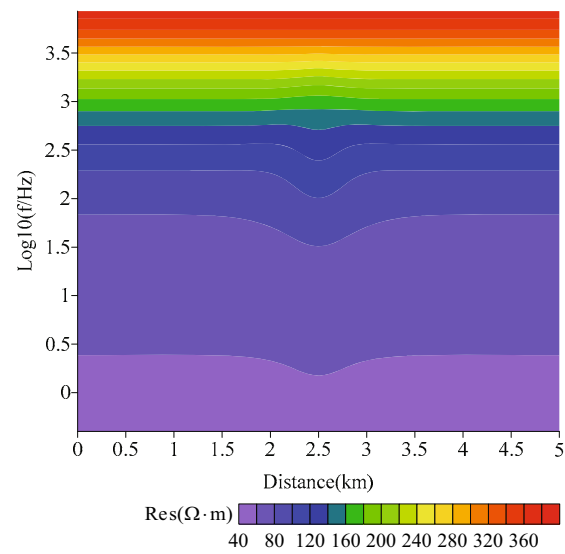

(a)

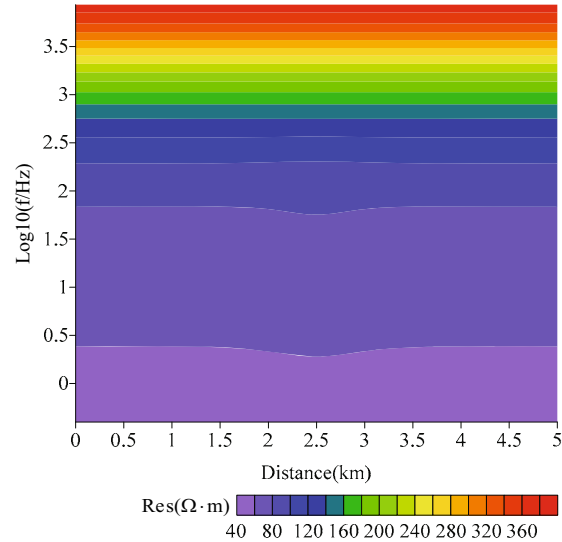

(b)

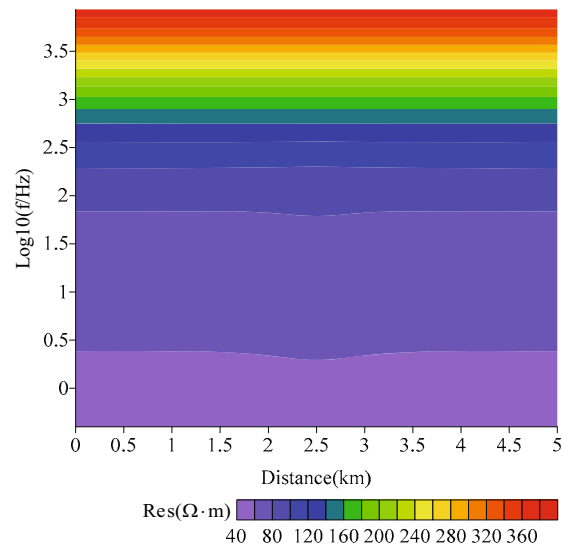

(c)

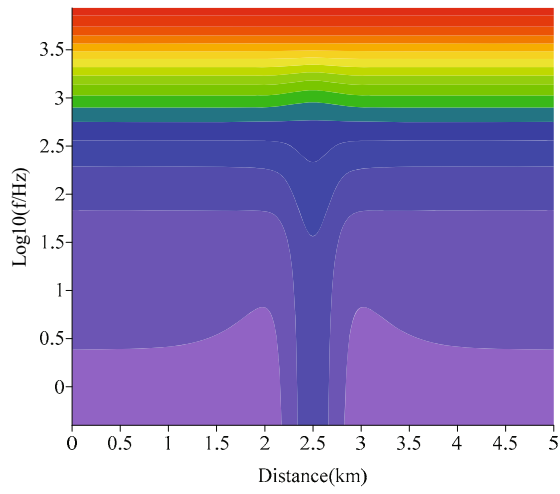

$\operatorname{Res}(\Omega \cdot \mathrm{m})$

4080120160200240280320360 TM mode $(h=100 \mathrm{~m})$

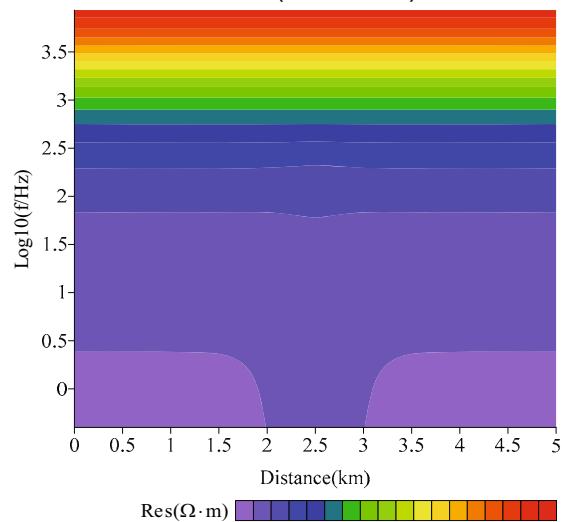

$40 \quad 80120160200240280320360$

TM mode $(h=350 \mathrm{~m})$

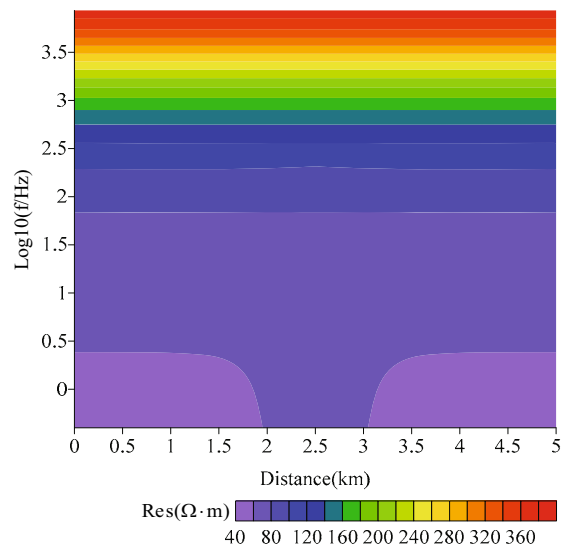

TM mode $(h=400 \mathrm{~m})$

Fig. 7. The apparent resistivity section diagrams of the high-resistance abnormal body of gas hydrate with different bury depths. 
thickness of permafrost in Muli coalfield, the gas hydrate stability zone (GHSZ) of the study area has been studied. The results showed that the top depth of the GHSZ is $171 \mathrm{~m}$, and the bottom depth of the GHSZ is $574 \mathrm{~m}$, respectively (Zhu et al. 2010). Besides, gas hydrate samples recovered from the study area are shallow-buried, ranging from 133 to $396 \mathrm{~m}$ in depth (Fig. 2). Therefore, for the above bury depth condition, the AMT method can be effectively used to identify and delineate the gas hydrate reservoir in the Qilian mountain permafrost.

\subsection{Influence of acquisition parameters on AMT inversion results}

Because the difference of electrical properties between the permafrost layer and gas hydrate reservoir is not that obvious, and gas hydrate occurs closely below the permafrost layer, the inversion results will be affected largely. So the geoelectric model built here will not consider the overlying permafrost layer. To reflect the general electrical properties of gas hydrate reservoir, the average resistivity, approximated to be $170 \Omega$.m, derived from Eq. 26 with porosity $10 \%$ and saturation $30 \sim 80 \%$ is used as the resistivity for inversion model. According to the resistivity logging data of the DK-1 hole (Fig. 3a, Table 3), the maximum ratio of resistivity value of gas hydrate reservoir to resistivity value of surrounding rock can be 10 (Lu et al. 2011, Yao et al. 2013). Therefore, to improve the inversion results and to better analyze the effect of acquisition data to inversion, the resistivity value of surrounding rock is set to be $17 \Omega . \mathrm{m}$. According to the electrical characteristics of gas hydrate, a typical geoelectrical model is built for gas hydrate reservoir in the study area (Fig. 8).

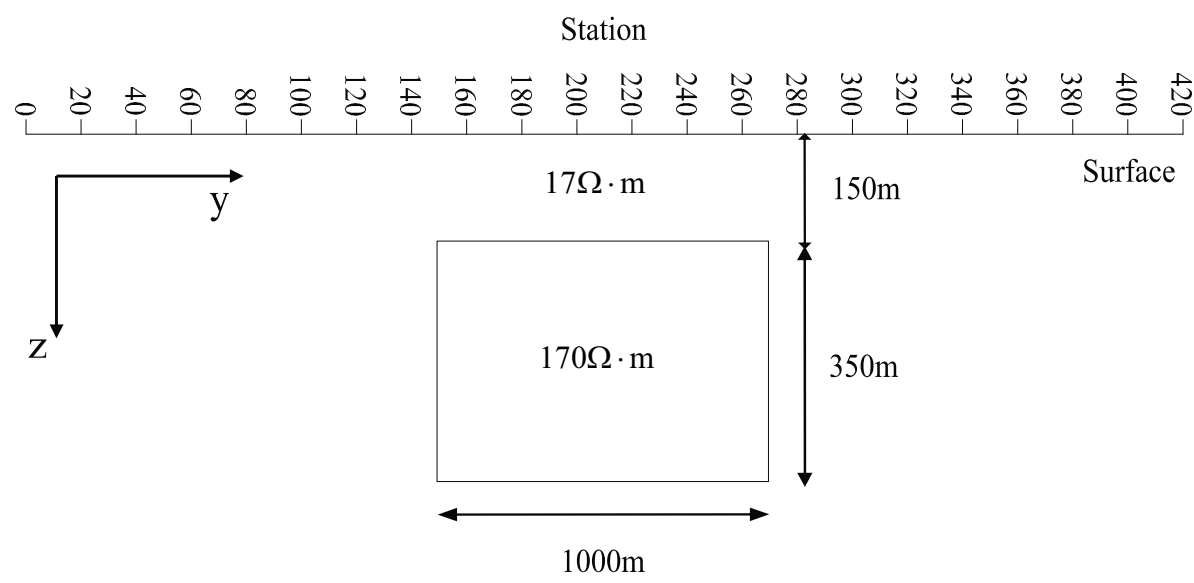

Fig. 8. Typical geoelectrical model of the high-resistance abnormal body of gas hydrate. 
Frequency points for AMT forward modeling

\begin{tabular}{|c|c|}
\hline Count & Frequency point $[\mathrm{Hz}]$ \\
\hline 91 & $\begin{array}{l}398,369,341,316,293,271,251,233,215,200,185,171,158,147, \\
136,126,117,108,100,92.6,85.8,79.4,73.6,68.1,63.1,58.4,54.1, \\
50.1,46.4,43.0,39.8,36.9,34.1,31.6,29.3,27.1,25.1,23.3,21.5, \\
\begin{array}{l}20.0,18.5,17.1,15.8,14.7,13.6,12.6,11.7,10.8,10.0,9.26,8.58, \\
7.94,7.36,6.81,6.31,5.84,5.41,5.01,4.64,4.30,3.98,3.69,3.42, \\
3.16,2.93,2.71,2.51,2.33,2.15,2.00,1.85,1.71,1.59,1.47,1.36, \\
1.26,1.17,1.08,1.00,0.926,0.858,0.794,0.736,0.681,0.631,0.584, \\
0.541,0.501,0.464,0.430,0.398\end{array}\end{array}$ \\
\hline 46 & $\begin{array}{l}398,341,293,251,215,185,158,136,117,100,85.8,73.6,63.1,54.1 \text {, } \\
46.4,39.8,34.1,29.3,25.1,21.5,18.5,15.8,13.6,11.7,10.0,8.58 \text {, } \\
7.36,6.31,5.41,4.64,3.98,3.42,2.93,2.51,2.15,1.85,1.59,1.36 \text {, } \\
1.17,1.00,0.858,0.736,0.631,0.541,0.464,0.398\end{array}$ \\
\hline 31 & $\begin{array}{l}398,316,251,200,158,126,100,79.4,63.1,50.1,39.8,31.6,25.1 \text {, } \\
20.0,15.8,12.6,10.0,7.94,6.31,5.01,3.98,3.16,2.51,2.00,1.58 \text {, } \\
1.26,1.00,0.794,0.631,0.501,0.398\end{array}$ \\
\hline 16 & $\begin{array}{l}398,251,158,100,63.1,39.8,25.1,15.8,10.0,6.31,3.98,2.51,1.58 \text {, } \\
1.00,0.631,0.398\end{array}$ \\
\hline 7 & $398,126,39.8,12.6,3.98,1.26,0.398$ \\
\hline
\end{tabular}

The parameters are as follows: frequencies for forward modeling range from 0.1 to $1000 \mathrm{~Hz}$, and 91 frequency points are deployed (Table 6), the length of survey line is $10.5 \mathrm{~km}$, station spacing is $25 \mathrm{~m}$, the scale of the high-resistance abnormal body of gas hydrate is $350 \times 1000 \mathrm{~m}$, and the bury depth is $150 \mathrm{~m}$. The response characteristics of forward modeling in TE and TM modes can be obtained by AMT simulation with FEM.

Response characteristics of the high-resistivity anomaly of gas hydrate in TE and TM modes can be seen clearly from the section diagrams of apparent resistivity and phases of impedance (Fig. 9), conductive to the analysis of influence of acquisition data on AMT inversion results. At the top around $100 \mathrm{~Hz}$ the high-resistivity anomalies appear in TE and TM modes (Fig. 9a, c). The high-resistivity anomaly area closes up around $1 \mathrm{~Hz}$ in TE mode, while the high-resistivity anomaly area does not close up in the low frequency part in TM mode. In the section diagrams of TE and TM modes (Fig. 9b, d), the high-resistivity anomalies appear around $100 \mathrm{~Hz}$, and close up at high frequencies, indicating that the simulation can reflect the configuration of the high-resistance abnormal body of gas hydrate. 


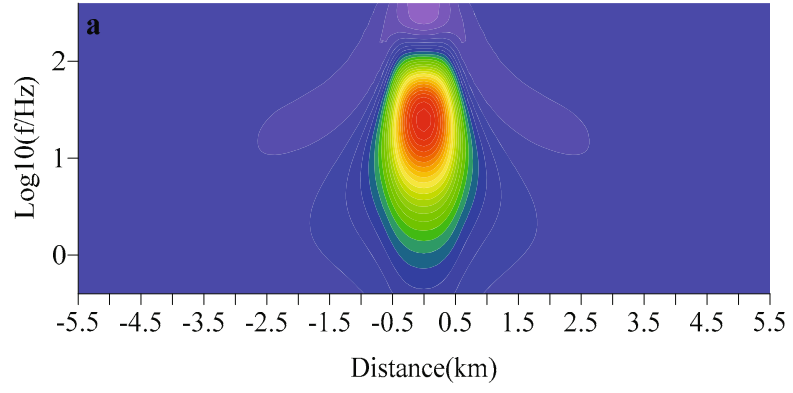

$\operatorname{Res}(\Omega \cdot \mathrm{m})$

151617181920212223242526272829

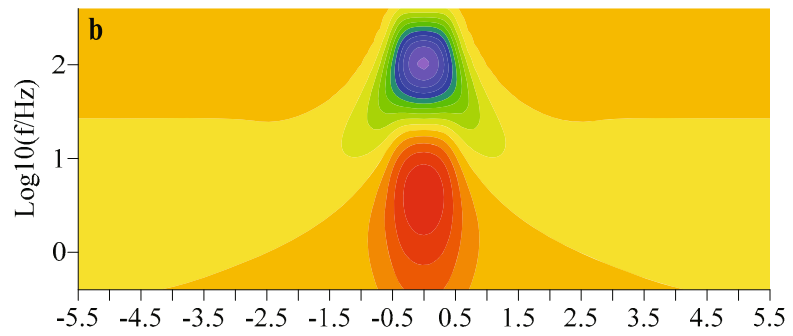

Distance $(\mathrm{km})$

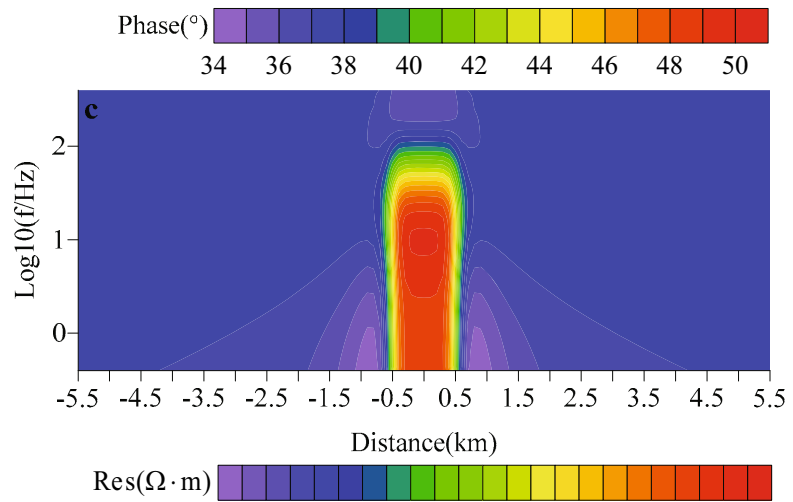

$\begin{array}{llllllllllll}13 & 15 & 17 & 19 & 21 & 23 & 25 & 27 & 29 & 31 & 33 & 35\end{array}$

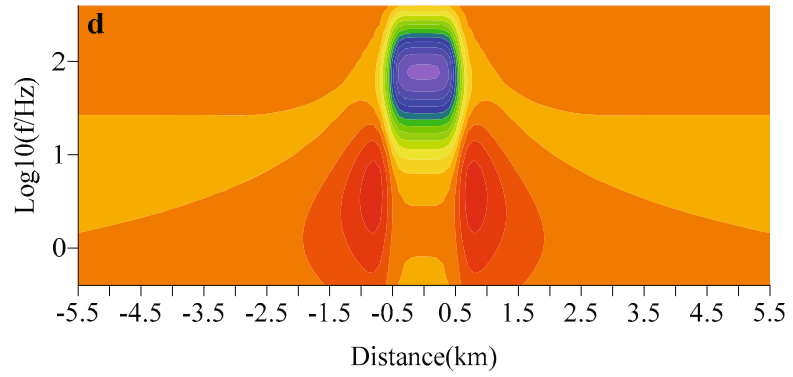

Phase $\left({ }^{\circ}\right)$

$-148-146-144-142-140-138-136-134-132$
Fig. 9. AMT forward modeling responses for typical high-resistance abnormal body of gas hydrate: (a) apparent resistivity of TE mode, (b) phase of TE mode, (c) apparent resistivity of TM mode, and (d) phase of TM mode. 


\subsubsection{Survey line length}

To investigate the influence of survey line length on the response characteristics of AMT inversion, the lengths of survey line are set to be 4, 3,2, and $1 \mathrm{~km}$. To better simulate the field data, $2 \%$ Gaussian noise is added to the original data, station spacing is $50 \mathrm{~m}$, frequency points range from 0.398 to $398 \mathrm{~Hz}$, and 46 frequency points are extracted at an interval of 0.06 in the log-domain (Table 6). The standardized parameter is set to be 10 , initial resistivity is set be $17 \Omega . \mathrm{m}$, and grid is set to be $92 \times 50$, with extended grid not included. Inversion mode is TE + TM.

Figure 10 shows the comparison diagrams of NLCG inversion results with different survey line lengths, where black frame indicates the size and position of actual model for the high-resistance abnormal body of gas hydrate. With the gradual increase of survey line length from 1 to $4 \mathrm{~km}$, the anomalies reflected by inversion are consistent with the actual model in size and position. When survey line length equals the width of the high-resistance abnormal body (Fig. 10d), the width of the high-resistivity anomaly by inversion is only about $800 \mathrm{~m}$, and the bottom boundary is about $550 \mathrm{~m}$. Inversion results do not coincide with the actual model. When survey line is twice the length of the width of the high-resistance abnormal body (Fig. 10c), the width of the high-resistivity anomaly by inversion is $970 \mathrm{~m}$. The top and bottom boundaries are consistent with the actual model, but the size of the anomaly is smaller than the actual model. When survey line length is more than triple the width of the high-resistance abnormal body (Fig. 10a-b), the size and position by inversion show good compatibility with the actual model.

From the above analysis it follows that, for AMT prospecting of gas hydrate in the Qilian Mountain permafrost, relatively longer survey line is more favorable to the identification of the high-resistance abnormal body. But with the increase of survey line length, expenses for field data acquisition and time for indoor data processing will increase correspondingly. Therefore, survey line length should be determined based on the actual occurrence of gas hydrate reservoir in the Qilian Mountain permafrost. Generally, double size of the possible occurrence region will be suitable, while triple size makes the best results.

\subsubsection{Station space}

To discuss the influence of station spacing on AMT inversion results, station spacings are defined to be $25,50,100$, and $200 \mathrm{~m}$. Survey line length is fixed to be $4 \mathrm{~km}$, and the other parameters are the same for the above-mentioned data.

Figure 11 shows the comparison diagrams of NLCG inversion results with different station spacing. With the increase of station spacing from 25 

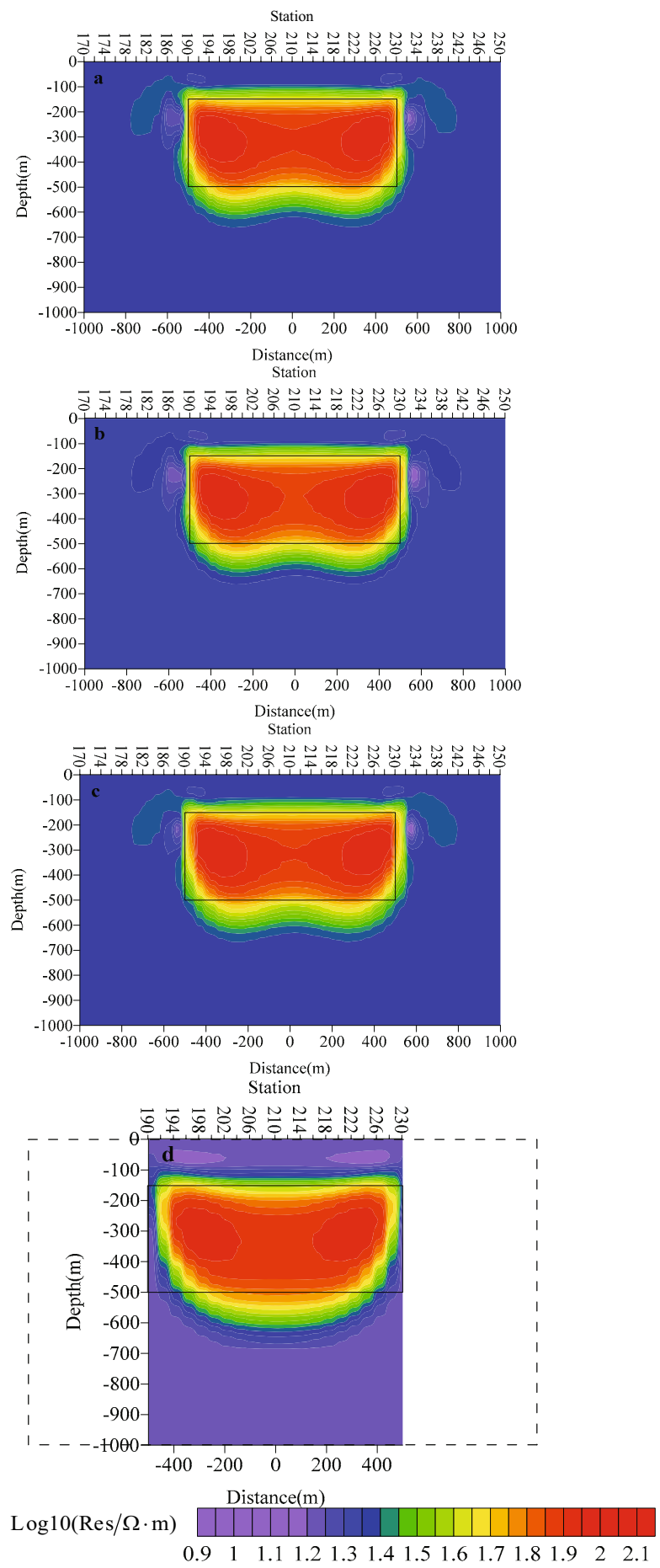

Fig. 10. 2D NLCG inversion results of the high-resistance abnormal body of gas hydrate with different survey line lengths: (a) $4 \mathrm{~km}$, (b) $3 \mathrm{~km}$, (c) $2 \mathrm{~km}$, and (d) $1 \mathrm{~km}$. 

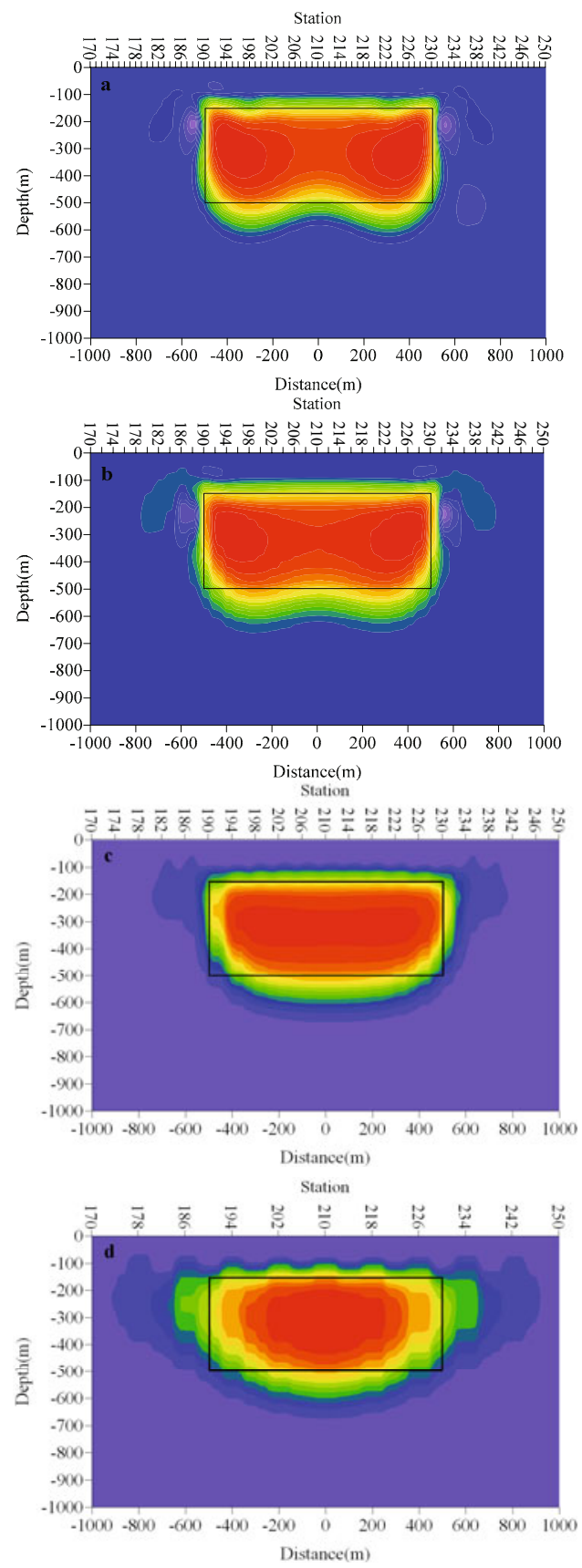

$\log 10(\operatorname{Res} / \Omega \cdot \mathrm{m})$

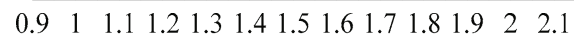

Fig. 11. 2D NLCG inversion results of the high-resistance abnormal body of gas hydrate with different station spacing: (a) $25 \mathrm{~m}$, (b) $50 \mathrm{~m}$, (c) $100 \mathrm{~m}$, and (d) $200 \mathrm{~m}$. 
to $200 \mathrm{~m}$, corresponding to the number of stations 41, 21, 11, and 5, AMT inversion results get worse, that is, the widths of anomalies decrease and the deviations get larger. When station spacings are 25 and $50 \mathrm{~m}$ (Fig. 11a-b), the size and position of high-resistivity anomaly by inversion are similar and coincide well with the actual model. When the spacing is $100 \mathrm{~m}$ (Fig. 11c), the width of high-resistivity anomaly by inversion is $900 \mathrm{~m}$, and the depths of top boundary and bottom boundary are consistent with the actual model, but the size of high-resistivity anomaly is smaller than the actual model. When spacing is $20 \mathrm{~m}$ (Fig. 11d), the size and position by inversion differ largely from the actual model. It cannot reflect the size and position of the high-resistance abnormal body of gas hydrate.

From above analysis it follows that relatively short station spacing is more favorable to the identification of the high-resistance abnormal body of gas hydrate. But with the decrease of station spacing, expenses for field data acquisition and time for indoor data processing will increase correspondingly. The law of gas hydrate distribution in the lateral areas between drill holes is not apparent, and the continuity is relatively poor (Fig. 2). So when the AMT method is carried out, the number of stations should be no less than 6 , and 11 stations make the best results.

\subsubsection{Number of frequency points}

To discuss the influence of the number of frequency points on AMT inversion results for gas hydrate reservoir, the numbers of frequency points are assumed to be 46,31, 16, and 7, and Table 6 gives the specific frequencies. The survey line length is fixed to be $4 \mathrm{~km}$, and the station spacing is set to be $50 \mathrm{~m}$. The other parameters are the same as for the above mentioned data.

Figure 12 shows the comparison diagrams of NLCG inversion results with different number of frequency points. With the decrease of the number of frequency points from 46 to 7 , corresponding to $10,7,4$, and 2 of the number of frequency points in the influence range of the high-resistivity anomaly $(100 \sim 1000 \mathrm{~Hz})$, AMT inversion results get worse, that is, the reflected size and position of anomalies deviate from the actual model gradually. When the numbers of frequency points are 46 and 31 (Fig. 12a-b), the size and position of the high-resistivity anomaly coincide well with the actual model. When the number of frequency points is 16 (Fig. 12c), the width of the high-resistivity anomaly by inversion is $970 \mathrm{~m}$. The top boundary and bottom boundary are consistent with the actual model, but the highresistivity anomaly is smaller than the actual model in size. When the number of frequency points is 7 (Fig. 12d), the width of the high-resistivity anomaly by inversion is $950 \mathrm{~m}$, and the bottom boundary is about $580 \mathrm{~m}$. The size and position of the high-resistivity anomaly by inversion do not coincide with the actual model. 

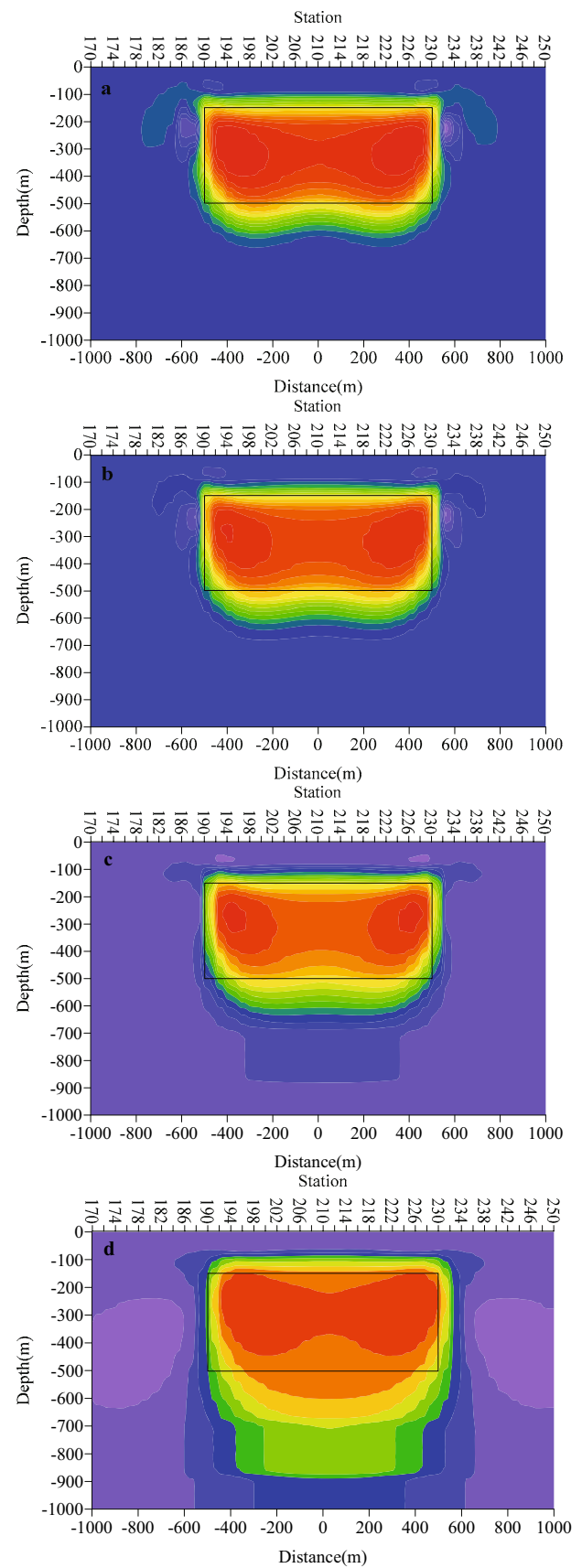

$\log 10(\operatorname{Res} / \Omega \cdot \mathrm{m})$

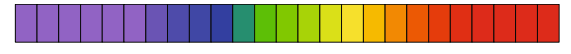

$\begin{array}{llllllllllllll}0.9 & 1 & 1.1 & 1.2 & 1.3 & 1.4 & 1.5 & 1.6 & 1.7 & 1.8 & 1.9 & 2 & 2.1\end{array}$

Fig. 12. 2D NLCG inversion results of the high-resistance abnormal body of gas hydrate with different numbers of frequency points: (a) 46, (b) 37 , (c) 16, and (d) 7 . 
From above analysis it follows that more frequency points are favorable to the identification of the high-resistance abnormal body of gas hydrate. But with the increase of frequency points, expenses for field data acquisition and time for indoor data processing will increase correspondingly. Gas hydrate samples recovered from the study area are shallow-buried, ranging from 133 to $396 \mathrm{~m}$ in depth (Fig. 2), which belongs to the high-frequency section of AMT method. Therefore, if the AMT method in this area is carried out, the number of frequency points set in high-frequency section $(100 \sim 1000 \mathrm{~Hz})$ should be no less than 3,4 points as best.

\section{CONCLUSIONS}

(1) Using the resistivity calculation model based on the Archie's equations for the gas hydrate reservoir, combined with resistivity logging data of gas hydrate scientific drilling holes in the Qilian Mountain permafrost, electrical characteristics of gas hydrate reservoirs of different lithology are analyzed to lay a foundation for the establishment of the geoelectrical model.

(2) The AMT response characteristics of the gas hydrate reservoir in the Qilian Mountain permafrost with variations of resistivity, occurrence scale and bury depth are simulated by finite element method, and the application range of AMT prospecting for the gas hydrate reservoir is obtained. If porosity is less than $5 \%$, saturation of gas hydrate is higher than $70 \%$, occurrence scale is less than $50 \mathrm{~m}$, or bury depth is greater than $500 \mathrm{~m}$, the AMT sounding cannot identify and delineate the favorable gas hydrate reservoir.

(3) With NLCG algorithm influences of acquisition parameters on AMT inversion results are studied, and an optimized acquisition parameters scheme favorable to prospecting the gas hydrate reservoir is obtained. Survey line should be twice the length of occurrence scale, while triple the length makes the best result. The number of stations in the possible occurrence region should be no less than 6 , while 11 stations will be optimal. Frequency points setting at high frequency section $(100 \sim 1000 \mathrm{~Hz})$ should be no less than 3, 4 points as best.

Acknowledgments. This work was supported by National Special Research Fund (Gas Hydrate Resource Exploration and Production Testing Project) (No. GZHL20110313) and National Natural Science Foundation of China (No. 41274185). We wish to thank the anonymous reviewers for their valuable and constructive comments and suggestions which helped us to improve our manuscript. 
Abdelzaher, M., J. Nishijima, G. EI-Qady, E. Aboud, O. Masoud, M. Soliman, and S. Ehara (2011), Gravity and magnetotelluric investigations to elicit the origin of Hammam Faraun hot spring, Sinai Peninsula, Egypt, Acta Geophys. 59, 3, 633-656, DOI: 10.2478/s11600-011-0006-4.

Archie, G.E. (1942), The electrical resistivity $\log$ as an aid in determining some reservoir characteristics, Trans. AIME 146, 1, 54-62, DOI: 10.2118/942054-G.

Balyavskii, V.V., and V.V. Sukhoi (2004), The method of audio-frequency magnetotelluric sounding in mineral exploration, Izv. - Phys. Solid Earth. 40, 6, 515-533.

Boswell, R., and T.S. Collett (2011), Current perspectives on gas hydrate resources, Energy Environ. Sci. 4, 1206-1215, DOI: 10.1039/c0ee00203h.

Boswell, R., G. Moridis, M. Reagan, and T.S. Collett (2011), Gas hydrate accumulation types and their application to numerical simulation. In: Proc. 7th Int. Conf. on Gas Hydrates (ICGH 2011), 17-22 July 2011, Edinburgh, Scotland, Manuscript No. 130.

Bronner, G., and J.P. Fourno (1992), Audio-magnetotelluric investigation of allochthonous iron formations in the Archaean Reguibat shield (Mauritania): structural and mining implications, J. Afr. Earth Sci. 15, 3-4, 341-351, DOI: 10.1016/0899-5362(92)90019-9.

Bybee, K. (2004), Natural gas technology/monetization: Overview of the Mallik gas-hydrate production research well, J. Petrol. Technol. 56, 4, 53-54, DOI: 10.2118/0404-0053-JPT.

Carcione, J.M., and D. Gei (2004), Gas-hydrate concentration estimated from P- and S-wave velocities at the Mallik 2L-38 research well, Mackenzie Delta, Canada, J. Appl. Geophys. 56, 1, 73-78, DOI: 10.1016/j.jappgeo.2004.04. 001.

Clerc, G., J.P. Décriaud, G. Doyen, M. Halbwachs, M. Henrotte, J. Rémy, and X.C. Zhang (1984), An automatic audio-magnetotelluric equipment, controlled by microprocessor, for the telesurveillance of the volcano Momotombo (Nicaragua), Surv. Geophys. 6, 3-4, 291-304, DOI: 10.1007/ BF01465544.

Coggon, J.H. (1971), Electromagnetic and electrical modeling by the finite element method, Geophysics 36, 1, 132-155, DOI: 10.1190/1.1440151.

Collett, T.S. (2002), Energy resource potential of natural gas hydrates, AAPG Bull. 86, 11, 1971-1992.

Collett, T.S. (2005), Results at Mallik highlight progress in gas hydrate energy resource research and development, Petrophysics 46, 3, 237-243.

Collett, T.S., M.W. Lee, W.F. Agena, J.J. Miller, K.A. Lewis, M.V. Zyrianova, R. Boswell, and T.L. Inks (2011), Permafrost-associated natural gas hydrate occurrences on the Alaska North Slope, Mar. Petrol. Geol. 28, 2, 279-294, DOI: 10.1016/j.marpetgeo.2009.12.001. 
Constable, S.C., R.L. Parker, and C.G. Constable (1987), Occam's inversion: A practical algorithm for generating smooth models from electromagenetic sounding data, Geophysics 52, 3, 289-300, DOI: 10.1190/1.1442303.

De Lugão, P.P., and P.E. Wannamaker (1996), Calculating the two-dimensional magnetotelluric Jacobian in finite elements using reciprocity, Geophys. J. Int. 127, 3, 806-810, DOI: 10.1111/j.1365-246X.1996.tb04060.x.

Dickens, G.R. (2001), The potential volume of oceanic methane hydrates with variable external conditions, Org. Geochem. 32, 10, 1179-1193, DOI: 10.1016/ S0146-6380(01)00086-9.

Fu, J.H., and L.F. Zhou (1998), Carboniferous-Jurassic stratigraphic provinces of the southern Qilian basin and their petrogeological features, Northwest Geosci. 19, 2, 47-54 (in Chinese).

Goldberg, S., and Y. Rotstein (1982), A simple form of presentation of magnetotelluric data using the Bostick transform, Geophys. Prosp. 30, 2, 211-216, DOI: $10.1111 /$ j.1365-2478.1982.tb01299.x.

Guo, X.W., and Y.H. Zhu (2011), Well logging characteristics and evaluation of hydrates in Qilian Mountain permafrost, Geol. Bull. China 30, 12, 1869-1873 (in Chinese).

Hestenes, M.R. (1973), Iterative methods for solving linear equations, J. Optimiz. Theory App. 11, 4, 323-334, DOI: 10.1007/BF00932484.

Hestenes, M.R., and E. Stiefel (1952), Methods of conjugate gradients for solving linear systems, J. Res. Nat. Bur. Stand. 49, 6, 409-436, DOI: 10.6028/ jres.049.044.

Hu, Z.Z., X.Y. Hu, and Z.X. He (2006), Pseudo-three-dimensional magnetotelluric inversion using nonlinear conjugate gradients, Chinese J. Geophys. 49, 4, 1111-1120, DOI: $10.1002 /$ cjg2.934.

Huo, Y.Y., and M. Zhang (2009), Full waveform inversion of gas hydrate reflectors in Northern South China Sea, Acta Geophys. 57, 3, 716-727, DOI: 10.2478/ s11600-009-0011-z.

Israil, M. (2006), Delineation of layer boundaries from smooth models obtained from the geoelectrical sounding data inversion, Acta Geophys. 54, 2, 126141, DOI: $10.2478 / \mathrm{s} 11600-006-0012-0$.

Koh, C.A., A.K. Sum, and E.D. Sloan (2012), State of the art: Natural gas hydrates as a natural resource, J. Nat. Gas Sci. Eng. 8, 132-138, DOI: 10.1016/ j.jngse.2012.01.005.

Lee, M.W., and T.S. Collett (2011), In-situ gas hydrate hydrate saturation estimated from various well logs at the Mount Elbert Gas Hydrate Stratigraphic Test Well, Alaska North Slope, Mar. Petrol. Geol. 28, 2, 439-449, DOI: 10.1016/j.marpetgeo.2009.06.007.

Li, X.S., B. Yang, G. Li, and B. Li (2012), Numerical simulation of gas production from natural gas hydrate using a single horizontal well by depressurization 
in Qilian Mountain permafrost, Ind. Eng. Chem. Res. 51, 11, 4424-4432, DOI: $10.1021 / \mathrm{ie} 201940 \mathrm{t}$.

Lin, Z.Z., Y. Li, W.L. Gao, G.S. Kong, and S.Z. Sun (2013), Physical character analysis of logging data for natural gas hydrate in Qilian Mountain permafrost area, Geophys. Geochem. Explor. 37, 5, 834-838.

Lu, Z.Q., Y.H. Zhu, Y.Q. Zhang, H.J. Wen, Y.H. Li, and C.L. Liu (2011), Gas hydrate occurrences in the Qilian Mountain permafrost, Qinghai Province, China, Cold Reg. Sci. Technol. 66, 2-3, 93-104, DOI: 10.1016/j. coldregions.2011.01.008.

Lu, Z.Q., Y.H. Zhu, H. Liu, Y.Q. Zhang, C.S. Jin, X. Huang, and P.K. Wang (2013a), Gas source for gas hydrate and its significance in the Qilian Mountain permafrost, Qinghai, Mar. Petrol. Geol. 43, 341-348, DOI: 10.1016/ j.marpetgeo.2013.01.003.

Lu, Z.Q., X.H. Xue, Z.W. Liao, and H. Liu (2013b), Source rocks for gases from gas hydrate and their burial depth in the Qilian Mountain permafrost, Qinghai: Results from thermal stimulation, Energy Fuels 27, 12, 7233-7244, DOI: 10.1021/ef4010797.

Mackie, R.L., J.T. Smith, and T.R. Madden (1994), Three-dimensional electromagnetic modeling using finite difference equations: The magnetotelluric example, Radio Sci. 29, 4, 923-935, DOI: 10.1029/94RS00326.

Moridis, G.J., T.S. Collett, M. Pooladi-Darvish, S. Hancock, C. Santamarina, R. Boswell, T.. Kneafsey, J. Rutqvist, M.B. Kowalsky, M.T. Reagan, E.D. Sloan, A.K. Sum, and C.A. Koh (2011), Challenges, uncertainties, and issues facing gas production from gas hydrate deposits, SPE Reserv. Eval. Eng. 14, 1, 76-112, SPE-131792, DOI: 10.2118/131792-PA.

Newman, G.A., and D.L. Alumbaugh (1997), 3D electromagnetic modeling using staggered finite differences. In: 1997 IEEE Int. Geosci. Remote Sens. Symp. "Remote Sensing - A Scientific Vision for Sustainable Development", 3-8 August 1997, Singapore, Vol. 2, 929-932, DOI: 10.1109/IGARSS.1997. 615301.

Newman, G.A., and D.L. Alumbaugh (2000), Three-dimensional magnetotelluric inversion using non-linear conjugate gradients, Geophys. J. Int. 140, 2, 410424, DOI: 10.1046/j.1365-246x.2000.00007.x.

Ogawa, Y., M. Uyeshima, Y. Honkura, H. Utada, and S. Koyama (1994), Audiofrequency magnetotelluric imaging of an active strike-slip fault, $J$. Geomagn. Geoelectr. 46, 5, 403-408, DOI: 10.5636/jgg.46.403.

Pang, S.J., X. Su, H. He, Q. Zhao, Y.H. Zhu, P.K. Wang, Y.H. Li, and Q.H. Li (2013), Geological controlling factors of gas hydrate occurrence in Qilian Mountain permafrost, China, Earth Sci. Front. 20, 1, 223-239 (in Chinese).

Rodi, W., and R.L. Mackie (2001), Nonlinear conjugate gradients algorithm for 2-D magnetotelluric inversion, Geophysics 66, 1, 174-187, DOI: 10.1190/ 1.1444893 . 
Ryan, W.B.F., S.M. Carbotte, J.O. Coplan, S. O’Hara, A. Melkonian, R. Arko, R.A. Weissel, V. Ferrini, A. Goodwillie, F. Nitsche, J. Bonczkowski, and R. Zemsky (2009), Global multi-resolution topography synthesis, Geochem. Geophys. Geosyst. 10, 3, DOI: 10.1029/2008GC002332.

Santos, F.A.M., A. Trota, A. Soares, R. Luzio, N. Lourenço, L. Matos, E. Almeida, J.L. Gaspar, and J.M. Miranda (2006), An audio- magnetotelluric investigation in Terceira Island (Azores), J. Appl. Geophys. 59, 4, 314-323, DOI: 10.1016/j.jappgeo.2005.12.001.

Santos, F.A.M., A.R.A. Afonso, and A. Dupis (2007), 2D joint inversion of dc and scalar audio-magnetotelluric data in the evaluation of low enthalpy geothermal fields, J. Geophys. Eng. 4, 1, 53-62, DOI: 10.1088/1742-2132/ 4/1/007.

Schnegg, P.A., B.V. Lequang, G. Fischer, and J.T. Weaver (1983), Audiomagnetotelluric study of a structure with a reverse fault, J. Geomagn. Geoelectr. 35, 11-12, 653-671, DOI: 10.5636/jgg.35.653.

Sloan, E.D., Jr. (1998), Clathrate Hydrates of Natural Gases, 2nd ed., Marcel Dekker Inc., New York.

Smith, J.T., and J.R. Booker (1991), Rapid inversion of two- and three-dimensional magnetotelluric data, J. Geophys. Res. 96, B3, 3905-3922, DOI: 10.1029/ 90JB02416.

Spichak, V.V. (2012), Evaluation of the feasibility of recovering the magma chamber's parameters by 3D Bayesian statistical inversion of synthetic MT data, Acta Geophys. 60, 3, 942-958, DOI: 10.2478/s11600-012-0008-x.

Strangway, D.W., C.M. Swift, Jr., and R.C. Holmer (1973), The application of audio-frequency magnetotellurics (AMT) to mineral exploration, Geophysics 38, 6, 1159-1175, DOI: 10.1190/1.1440402.

Sun, Z.J., Z.B. Yang, H. Mei, A.H. Qin, F.G. Zhang, Y.L. Zhou, S.Y. Zhang, and B.W. Mei (2014), Geochemical characteristics of the shallow soil above the Muli gas hydrate reservoir in the permafrost region of the Qilian Mountains, China, J. Geochem. Explor. 139, 160-169, DOI: 10.1016/j.gexplo. 2013.10.006.

Tikhonov, A.N., and V.Y. Arsenin (1978), Solutions of ill-posed problems, Math. Comput. 32, 144, 1320-1322, DOI: 10.2307/2006360.

Wang, P.K., Y.H. Zhu, Z.Q. Lu, X. Huang, S.J. Pang, and S. Zhang (2014), Gas hydrate stability zone migration occurred in the Qilian Mountain permafrost, Qinghai, Northwest China: Evidences from pyrite morphology and pyrite sulfur isotope, Cold Reg. Sci. Technol. 98, 8-17, DOI: 10.1016/ j.coldregions.2013.10.006.

Wang, T. (2010), Gas hydrate resource potential and its exploration and development prospect of the Muli coalfield in the northeast Tibetan plateau, Energ. Explor. Exploit. 28, 3, 147-158, DOI: 10.1260/0144-5987.28.3.147. 
Wannamaker, P.E. (1991), Advances in three-dimensional magnetotelluric modeling using integral equations, Geophysics 56, 11, 1716-1728, DOI: 10.1190/ 1.1442984 .

Wannamaker, P.E., J.A. Stodt, and L. Rijo (1987), A stable finite element solution for two-dimensional magnetotelluric modelling, Geophys. J. Int. 88, 1, 277296, DOI: 10.1111/j.1365-246X.1987.tb01380.x.

Wu, Q.B., G.L. Jiang, and P. Zhang (2010), Assessing the permafrost temperature and thickness conditions favorable for the occurrence of gas hydrate in the Qinghai-Tibet Plateau, Energ. Conv. Manage. 51, 4, 783-787, DOI: 10.1016/j.enconman.2009.10.035.

Xiao, K., C.C. Zou, B. Xiang, and J.Q. Liu (2013), Acoustic velocity log numerical simulation and saturation estimation of gas hydrate reservoir in Shenhu area, South China Sea, Sci. World J. 2013, 101459, DOI: 10.1155/2013/ 101459.

Xiong, Z.H., and A.C. Tripp (1997), 3-D electromagnetic modeling for near-surface targets using integral equations, Geophysics 62, 4, 1097-1106, DOI: 10.1190/1.1444210.

Xu, S.Z. (1994), The Finite Element Method in Geophysics, Science Press, Beijing (in Chinese).

Yamaguchi, S., Y. Ogawa, K. Fuji-ta, N. Ujihara, H. Inokuchi, and N. Oshiman (2010), Audio-frequency magnetotelluric imaging of the Hijima fault, Yamasaki fault system, southwest Japan, Earth Planets Space 62, 4, 401-411, DOI: $10.5047 /$ eps.2009.12.007.

Yang, R., P. Yan, N.Y. Wu, Z.B. Sha, and J.Q. Liang (2014), Application of AVO analysis to gas hydrates identification in the northern slope of the South China Sea, Acta Geophys. 62, 4, 802-817, DOI: 10.2478/s11600-013-0193-2.

Yao, D.W., S.M. Wang, D. Lei, W. Zhu, and G. Wang (2013), Application of CSAMT to Qilian Mountain permafrost region gas hydrate investigation, Chin. J. Eng. Geophys. 10, 2, 132-137 (in Chinese).

Zhao, J.F., T. Yu, Y.C. Song, D. Liu, W.G. Liu, Y. Liu, M.J. Yang, X.K. Ruan, and Y.H. Li (2013), Numerical simulation of gas production from hydrate deposits using a single vertical well by depressurization in the Qilian Mountain permafrost, Qinghai-Tibet Plateau, China, Energy 52, 308-319, DOI: 10.1016/j.energy.2013.01.066.

Zhu, Y.H., Y.Q. Zhang, H.J. Wen, Z.Q. Lu, Z.Y. Jia, Y.H. Li, Q.H. Li, C.L. Liu, P.K. Wang, and X.W. Guo (2010), Gas hydrates in the Qilian Mountain permafrost, Qinghai, Northwest China, Acta Geol. Sin. (Engl. Ed.) 84, 1, 110, DOI: $10.1111 /$ j.1755-6724.2010.00164.x.

Received 11 June 2014 Received in revised form 10 August 2014 